\title{
O carvão da Jazida de Morungava (RS, Brasil): Caracterização petrográfica, química e tecnológica das camadas de carvão do poço de exploração CBM 001-MO-RS
}

\author{
Gustavo SIMÃO \& Wolfgang KALKREUTH
}

Programa de Pós-graduação em Geociências, Instituto de Geociências, Universidade Federal do Rio Grande do Sul. Av. Bento Gonçalves, 9.500, CEP 91.540-000, Porto Alegre, Brasil (simao.geologia@gmail.com, wolfgang.kalkreuth@ufrgs.br).

Recebido em 02/2016. Aceito para publicação em 07/2017. Versão online publicada em 21/10/2017 (www.pesquisasemgeociencias.ufrgs.br)

\begin{abstract}
Resumo - Tendo em vista a necessidade ampliação da matriz energética nacional, torna-se premente desenvolver estudos em jazidas carboníferas não exploradas (e.g. Jazida de Morungava), onde pesquisas ulteriores datam da década de 1980. A fonte mineral situa-se no nordeste do Rio Grande do Sul, ocupando uma área de $250 \mathrm{~km}^{2}$. Para avaliar o potencial da jazida carbonífera (CBM001-MO-RS) e sua economicidade, foi realizada a caracterização petrográfica, química e tecnológica das camadas obtidas (num total de seis), com $387,70 \mathrm{~m}$ de profundidade, espessura cumulativa de carvão de 9,22 m. Obteve-se um total de 27 amostras, utilizadas à determinação dos seguintes parâmetros: descrição de litotipos do carvão, refletância da vitrinita, contagem de macerais, análises imediatas, poder calorífico superior, enxofre total, difração de raios-X e teste de beneficiamento. 0 litotipo carvão fosco predomina nas amostras, com um rank variando de carvão betuminoso alto volátil A a antracito. As distintas camadas apresentam progressiva intrusão vulcânica sotoposta. 0 grupo maceral vitrinita predomina nos carvões na porção inferior, enquanto inertinita predomina na superior. Matéria mineral tende a apresentar acréscimos da base ao topo. Os carvões apresentaram elevados teores de cinza (>50\% m.b.s.), matéria volátil (6,04-30,69\% m.b.s), enxofre $(0,20-2,88 \%$ m.b.s.) e poder calorífico superior (777-4.732 Kcal/Kg). Há predomínio mineralógico de quartzo, caulinita, e illita. Muitas das camadas são classificadas como rocha carbonosa $(>50 \%$ cinza/b.s.). Os ensaios de beneficiamento indicaram baixo rendimento ( $<7 \%$ vol.) na obtenção de produtos nobres.
\end{abstract}

Palavras-chave: Bacia do Paraná, Jazida de Morungava, petrologia do carvão, reflectância da vitrinita, testes de afunda flutua.

Abstract - THE COAL-BEARING STRATA OF THE MORUNGAVA COALFIELD (RS, BRAZIL): PETROGRAPHIC,
CHEMISTRY AND TECHNOLOGICAL CHARACTERIZATION OF COAL SEAMS FROM BOREHOLE CBM 001-MO-
RS. Considering the need to expand the national energy matrix, it is imperative to develop studies
on unexplored coal deposits (eg Morungava Reservoir), where further research dates back to the
1980s. The mineral source is located in the northeast of Rio Grande do Sul South, occupying an
area of $250 \mathrm{~km} 2$. In order to evaluate the potential of the coal deposit (CBM-001-MO-RS) and its
economicity, the petrographic, chemical and technological characterization of the layers obtained
(a total of six), with a depth of $387.70 \mathrm{~m}$, Coal of $9.22 \mathrm{~m}$. A total of 27 samples were used to determi-
ne the following parameters: charcoal lithotypes, vitrinite reflectance, maceral counts, immediate
analyzes higher calorific value, total sulfur, X-ray diffraction and processing test. The lithotype of
frosted coal predominates in the samples, with a rank ranging from high bituminous coal volatile A
to anthracite. The distinct layers present progressive underwater volcanic intrusion. The vitrinite
maceral group predominates in the coals in the lower portion, while the intinite predominates in
the upper one. Mineral matter tends to present increases from the base to the top. The coals pre-
sented high levels of ash ( $>50 \%$ mbs), volatile matter (6.04-30.69\% mbs), sulfur ( $0.20-2.88 \%$ mbs)
and higher calorific value ( $777-4,732 \mathrm{Kcal} / \mathrm{Kg}$ ). There is mineralogical predominance of quartz,
kaolinite, and illite. Many of the layers are classified as carbonaceous rock ( $>50 \%$ gray / b.s.). The
beneficiation tests indicated low yield (<7\% vol.) in obtaining noble products. Keywords: Paraná Basin, Morungava coalfield, coal petrology, vitrinite reflectance, sink and flout tests. 


\section{Introdução}

Considerando uma escala produtiva em nível mundial, o carvão, como recurso energético, é o combustível fóssil mais abundante do planeta, com reservas provadas da ordem de 847,5 bilhões de toneladas. Este volume mineral é suficiente para atender a demanda atual por 130 anos (ANEEL, 2008). Além da farta oferta deste recurso mineral, suas reservas caracterizam-se por serem geograficamente bem distribuídas, assim como o comportamento dos preços é outra vantagem competitiva. Adversamente, considerando como exemplo outro combustível fóssil, constata-se que as cotações do petróleo e derivados têm se caracterizado pela extrema volatilidade. No caso da commodity carvão, no entanto, registraram-se movimentos suaves ao longo dos últimos dez anos (ANEEL, 2008).

Observando-se a geração de energia elétrica em escala global, o IEA (2010) relata que o carvão apresenta um dos mais baixos custos de produção, menor risco de variações de preço e de interrupção de suprimento, além de ganhos de eficiência nas usinas termelétricas com a utilização de tecnologias limpas.

Os recursos mapeados de carvão no Brasil, considerando reservas medidas e inferidas, ultrapassam 32 bilhões de toneladas (EPE, 2015) e estão contidos na sucessão de rochas vulcano-sedimentares da Bacia do Paraná. Estas reservas estão situadas principalmente, nos estados do Rio Grande do Sul e Santa Catarina e em menor porcentagem no Paraná e São Paulo.

As camadas de carvão das jazidas sul-brasileiras integram a Formação Rio Bonito, locada estratigraficamente na sequência Gondwana I, do pacote de rochas sedimentares da Bacia do Paraná, de idade Permiana (Milani et al., 2007). A parte preponderante das jazidas apresenta linhas de afloramento das suas camadas de carvão, relacionadas à borda erosiva leste da Bacia do Paraná. As exceções são as porções leste da Jazida de Morungava/Chico Lomã, sul da Jazida Sul-Catarinense e a totalidade da Jazida Santa Terezinha, que se encontram sob a cobertura de sedimentos Cenozoicos da Planície Costeira (Gomes et al., 1998).

Diante da crescente demanda por energia elétrica no país, em contrapartida a disponibilidade cada vez menor de áreas para o aproveitamento hídrico na geração de energia, a utilização do carvão, vinculado ao emprego de tecnologias limpas, favorece o desenvolvimento futuro de uma matriz energética diversificada, segura e sustentável no longo prazo (Simão, 2012). Nesse contexto, considera-se de extrema relevância o desenvolvimento de estudos nas jazidas carboníferas ainda não exploradas. A Jazida de Morungava se adequa ao atual cenário, por tratar-se de uma reserva fóssil nunca explorada comercialmente e na qual as últimas pesquisas exploratórias datam da década de 1980.

Tendo como referencial a exposição preliminar, promoveu-se a perfuração de um poço designado de CBM 001-MO-RS, de caráter prospectivo/ exploratório na Jazida de Morungava, com o intento de melhor caracterizar o carvão desta potencial jazida carbonífera, bem como determinar sua real viabilidade econômica à produção de carvão e gás natural. 0 citado poço foi perfurado entre os dias 30/11/2011 a 13/02/2012, no município de Gravataí, RS. De forma adicional, os estudos correspondentes tem como objetivo o conhecimento integrado dos aspectos geológicos, propriedades petrográficas, químicas, físico-químicas e de características de beneficiamento de amostras de carvão.

0 presente estudo caracteriza-se por seu pioneirismo no que concerne ao conhecimento dos carvões da Jazida de Morungava, analisando a influência da maturação térmica causada por uma intrusão ígnea no grau de carbonificação das camadas de carvão. Adicionalmente, foram conduzidas avaliações relativas à economicidade dos carvões da jazida, sendo estes realizados por meio de testes de beneficiamento, envolvendo a redução dos teores de cinzas e enxofre, em contrapartida a um incremento do teor de matéria orgânica, resultando no aumento do poder calorífico.

\section{2 Área de estudo, materiais e métodos}

\subsection{Localização da Área de Estudo}

A Jazida de Morungava está localizada próxima à margem atlântica brasileira, na porção nordeste do Rio Grande do Sul, estendendo-se longitudinalmente em direção ao litoral norte do estado (Fig. 1).

As áreas com reservas econômicas de carvão da Jazida de Morungava abrangem uma extensão de aproximadamente $1.200 \mathrm{~km}^{2}$ (Ferreira et al., 1978). No Projeto Carvão do Rio Grande do Sul, Ferreira et al. (1978) seccionaram a porção principal da jazida em dois blocos: Bloco Norte (dá o nome a Jazida de Morungava) e Bloco Sul (Barro Vermelho) (Fig. 2). Existem mais dois blocos considerados isolados por Ferreira et al. (1978), denominados Gravataí Leste e Gravataí Oeste, contudo, no trabalho de Zanini \& Pimentel (2006), o bloco leste aparece interligado ao corpo principal da 


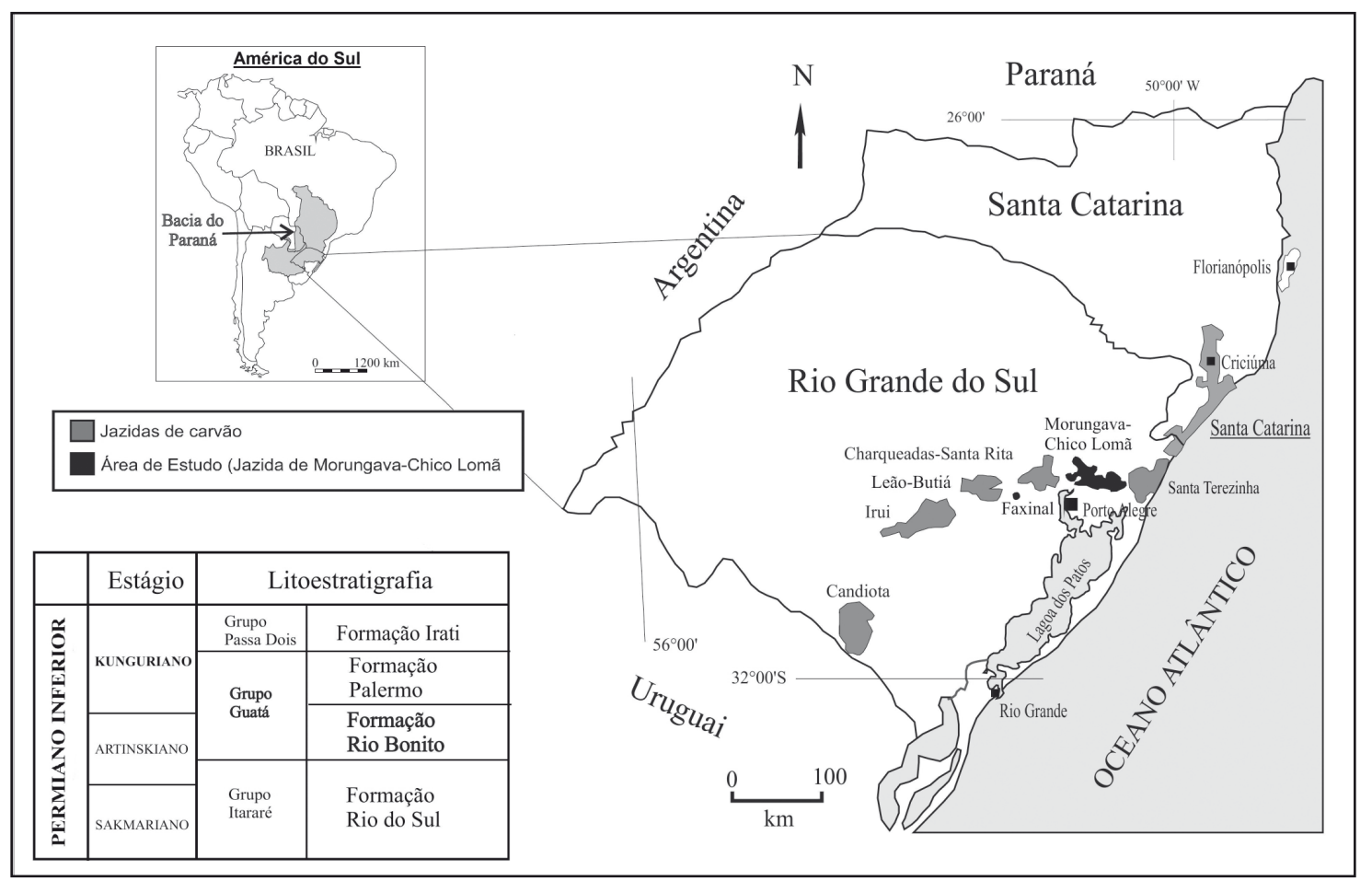

Figura 1. Localização da Bacia do Paraná, ressaltando a distribuição das jazidas de carvão nos estados do Rio Grande do Sul e Santa Catarina (cinza), com destaque em preto para a Jazida de Morungava; no quadro interno destaca-se a litoestratigrafia da Formação Rio Bonito (modificado de Kalkreuth et al., 2006).

Figure 1. Paraná Basin location map, showing the distribution of the coalfields in the Rio Grande do Sul and Santa Catarina States. The Morungava-Chico Lomã coalfield is marked in black. The inserted table shows the lithostratigraphic position of the coal-bearing Rio Bonito Formation (modified from Kalkreuth et al., 2006).

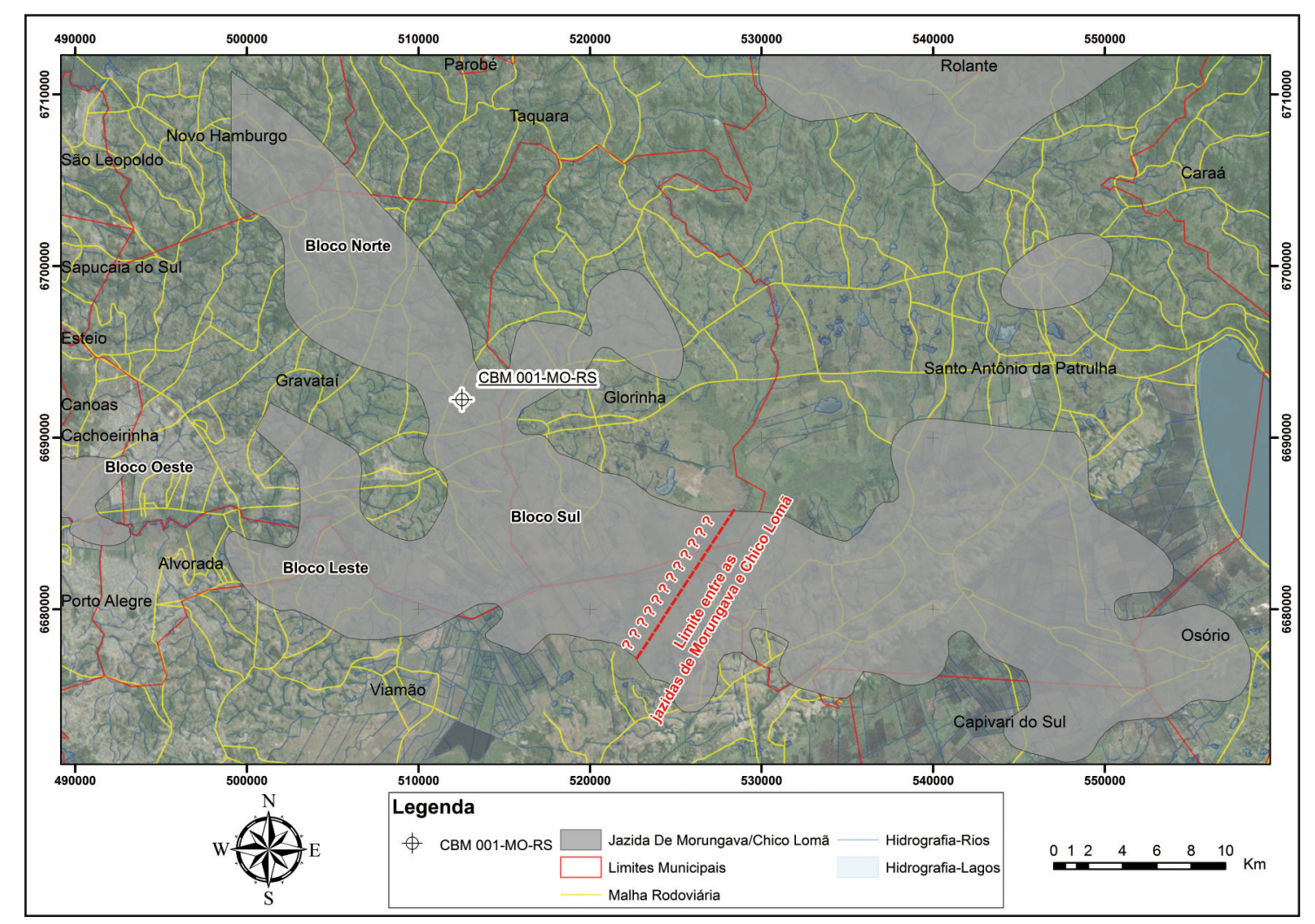

Figura 2. Mapa mostrando a Jazida de Morungava/Chico Lomã e a localização do poço de exploração CBM 001-MO-RS (modificado de Süffert, 1997; Zanini \& Pimentel, 2006).

Figure 2. Map showing the Morungava/Chico Lomã coalfield and the location of exploration borehole CBM 001-MO-RS (modified from Süffert, 1997; Zanini \& Pimentel, 2006). 
jazida (Fig. 2). Quanto à cobertura, o bloco norte apresenta até $450 \mathrm{~m}$, enquanto o Bloco Sul apresenta em média $100 \mathrm{~m}$ de espessura de cobertura.

No presente trabalho, foi utilizada a delimitação da Jazida de Morungava/Chico Lomã de Zanini \& Pimentel (2006), na qual as jazidas de Morungava e Chico Lomã são apresentadas de forma indivisa (Fig. 2). Cabe salientar que os limites dessas jazidas, ou mesmo a divisão entre as mesmas, carecem de trabalhos confirmatórios; parte delas é considerada duvidosa ou completamente em aberto.

\subsection{Contexto geológico}

A área de estudo encontra-se inserida nos domínios geomorfológicos da Planície Costeira e da Depressão Central do Estado do Rio Grande do Sul (Aboarrage \& Lopes, 1986). Os altos do embasamento, representando o domínio do Escudo Sul Rio-grandense, podem ser observados circundados pela Jazida de Morungava, nas proximidades da área urbana de Gravataí, demonstrando o forte controle estrutural da sedimentação gondwânica inferior que preenchia vales e depressões. Observa-se, bem definido, um paleovale denominado de "paleovale de Morungava" por Bossi \& Piccoli (1979b, 1980b).

As camadas de carvão da Jazida de Morungava estão contidas no contexto geológico da borda sul da Bacia do Paraná, que constitui uma grande bacia intracratônica disposta na parte central-leste da Plataforma Sul-Americana.

Com uma área total de $1.500 .000 \mathrm{~km}^{2}$ (Milani, 2000), a Bacia do Paraná ocupa cerca de 1.000.000 $\mathrm{km}^{2}$ no território brasileiro (Schneider et al., 1974), abrangendo partes dos territórios dos estados de Mato Grosso, Mato Grosso do Sul, Goiás, São Paulo, Minas Gerais, Paraná, Santa Catarina e Rio Grande do Sul. O seu registro estratigráfico compreende um pacote sedimentar-magmático com uma espessura total máxima em torno de $7 \mathrm{~km}$ em seu depocentro. 0 conjunto de rochas sedimentares e vulcânicas que constituem a Bacia do Paraná foi originado pela superposição de sequências depositadas em diferentes ambientes (Zalán et al., 1990).

0 preenchimento sedimentar da bacia foi dividido em seis sequências deposicionais. Os estratos onde o carvão ocorre correspondem à unidade litoestratigráfica denominada de Formação Rio Bonito, do Grupo Guatá (Schneider et al., 1974), localizada no topo da terceira supersequência, denominada de Gondwana I (Carbonífera/Triássico Inferior), que constitui espessas sequências sedi- mentares, atingindo $2.800 \mathrm{~m}$ no depocentro da bacia (Milani et al., 2007).

Os sedimentos da Formação Rio Bonito foram depositados no intervalo Sakmariano/Artinskiano (Permiano Inferior). As camadas de carvão têm características que são indicativas de uma origem límnico-telmática, onde o material que deu origem a turfeira é constituído por pteridófitas e plantas herbáceas (e.g. Glossopteris e Gangamopteris), acumuladas após algum transporte, resultando em camadas de carvão hipoautóctones, ricas em inertinita (Corrêa da Silva, 2004).

Segundo Bortoluzzi et al. (1980), compõem a Jazida de Morungava uma série de 7 camadas de carvão e alguns leitos de carvão. As camadas 1 a 6 encontram-se na porção superior da Formação Rio Bonito enquanto a camada 7 está na porção basal. 0 pacote carbonoso que contem as camadas 1 a 6 apresenta aproximadamente $21 \mathrm{~m}$ de espessura, estando situado a aproximadamente $35 \mathrm{~m}$ abaixo do contato entre as formações Palermo e Rio Bonito. Por sua vez o pacote contendo a camada 7 é muitas vezes relacionado às rochas do Grupo Itararé, descontínuo, com espessura centimétrica, podendo ser encontrado intercalado com rochas de granulometria mais grosseira. Na área da Jazida de Morungava, a Formação Rio Bonito, está em muitos casos em contato direto com o embasamento cristalino.

\subsection{Metodologia}

\subsubsection{Locação e execução do poço exploratório CBM 001-MO-RS}

O poço CBM 001-MO-RS está locado nas coordenadas UTM em SIRGAS 2000 (22J E 512.538,55 $\mathrm{m} / \mathrm{N}$ 6.692.221,23 m), sendo que o local da boca do poço encontra-se na cota altimétrica de 63,453 $\mathrm{m}$. Por sua vez a escolha do local de instalação do poço foi obtida a partir da interpretação de informações de 43 poços pré-existentes na área de estudo, os quais foram construídos nas décadas de 1970 e 1980 pelo Serviço Geológico do Brasil (CPRM) e Departamento Nacional de Produção Mineral (DNPM), no âmbito dos projetos Carvão do Rio Grande do Sul e Projeto Gravataí-Torres.

Considerando as informações obtidas quando da avaliação/estudo dos 43 poços, elaborou-se um banco de dados que serviu de subsídio à produção de mapas de isolinhas. Estes foram gerados por meio de análise geoestatística do tipo krigagem, realizada via interpolação de informações pertinentes ao desenvolvimento do trabalho como: espessura das camadas de carvão, espessura cumu- 
lativa das camadas de carvão, profundidade da primeira camada de carvão, além de mapas de cobertura de material inconsolidado e profundidade do embasamento cristalino.

Cabe ressaltar que a localização do poço exploratório levou em consideração, principalmente, os mapas de espessura cumulativa de carvão e profundidade da primeira camada de carvão (Fig. 3). A análise foi realizada desta forma, tendo em vista que os alvos iniciais do trabalho eram avaliar as camadas de carvão quanto a suas características, potencial econômico e seu potencial para presença de metano adsorvido (CBM: Coalbed Methane). 0 trap do gás contido na microporosidade do carvão necessita de espessuras de cobertura superiores a $300 \mathrm{~m}$, medida que balizou a escolha do local do poço.

Após a definição do local a ser iniciada a sondagem, os trabalhos relativos à execução do poço CBM 001-MO-RS iniciaram-se no dia 30 de novembro de 2011, encerrando-se em 13 de fevereiro de 2012. O trabalho foi realizado pela empresa SONDAP Sondagens e Perfurações Especiais Ltda. 0 método utilizado foi Wireline Core Retrieval, rotativo em diamante, com testemunhos retirados em barriletes de $3 \mathrm{~m}$ de comprimento. 0 poço foi perfurado até a profundidade de 387,30 m (Fig. 4A), amostrado por testemunhos de sondagem com diâmetro de $47 \mathrm{~mm}$.

\subsubsection{Amostragem e preparação}

As amostras de carvão foram preparadas de forma a manter a representatividade e qualidade das análises. Para tanto, foram submetidas à catalogação, secagem $\left(\leq 40^{\circ} \mathrm{C}\right)$ e corte dos testemunhos ao meio. A metade dos testemunhos destinada aos trabalhos de caracterização foi dividida em duas porções, destinadas a diferentes análises; a outra guardada para trabalhos futuros.

Uma das porções utilizadas foi submetida à preparação conforme a norma D-2013 (ASTM, 2007), a qual consiste na britagem em um britador do tipo mandíbula, seguida por homogeneização por peneiramento na malha $<4,75 \mathrm{~mm}$. Cada uma das amostras foi então quarteada em subamostras, destinadas a análises imediatas, poder calorífico superior e enxofre total (tamanho de grão menor que 200 mesh) e análises petrográficas (tamanho de grão entre $0,25-0,80 \mathrm{~mm}$ ), para fins de confecção de seções polidas.

A outra porção do testemunho foi destinada aos ensaios de beneficiamento gravimétrico, realizados por meio de ensaios com líquidos densos. Tais amostras foram submetidas à britagem, com homogeneização por peneiramento na malha < $12,8 \mathrm{~mm}$ conforme a metodologia descrita na NBR 8738 (ABNT, 1985). Os produtos obtidos a partir dos ensaios foram submetidos a análises imediatas, poder calorífico e petrográficas.

\subsubsection{Análise petrológica do carvão}

A descrição dos litotipos do carvão foi realizada no momento entre o corte dos testemunhos em duas porções e a britagem, e se baseou na metodologia de classificação entre carvão fosco e brilhando descrita em Diessel (1965) (Quadro 1). A preparação das amostras para as análises óticas foi feita de acordo com os procedimentos padronizados por Bustin et al. (1983). Conforme Marchioni \& Kalkreuth (1991), pode existir uma relação direta entre o conteúdo de litotipos brilhantes e o conteúdo de vitrinita, igualmente como conteúdo de inertinita e matéria mineral tendem a aumentar com a diminuição dos componentes brilhantes.

0 grau de carbonificação (rank) das amostras de carvão foi determinado através das medidas do poder refletor da vitrinita (ISO, 2009a: 7404-5) e a classificação segundo a norma para classificação de carvão (UN, 1998). Como esta norma utiliza com preceitos analíticos internacionais e as análises imediatas, foram realizadas segundo as normas técnicas nacionais, foi realizada uma leitura comparativa das mesmas, ficando evidenciado que a utilização de tais resultados na classificação não ocasionaria distorção nos resultados.

A determinação dos grupos macerais, sua distinção, e o conteúdo de matéria mineral estão em consonância as metodologias da Norma (ISO, 2009b: 7404-3) e das classificações expostas em ICCP (1998, 2001). Os resultados das análises petrográficas são expressos em porcentagem em volume.

\subsubsection{Análises imediatas, químicas e mineralógicas}

As análises imediatas, nas quais se determinaram os teores de umidade, cinzas, matéria volátil, foram realizadas segundo as normas NBR 8293 (ABNT, 1983a), NBR 8289 (ABNT, 1983b) e NBR 8290 (ABNT, 1983c), respectivamente, enquanto o carbono fixo foi estabelecido a partir da diferença entre a soma dos valores de cinza, umidade e matéria volátil e $100 \%$. 0 conteúdo de enxofre total foi determinado segundo a norma NBR 8295 (ABNT, 1983d).

0 poder calorífico superior foi quantificado utilizando-se bomba calorimétrica segundo a 

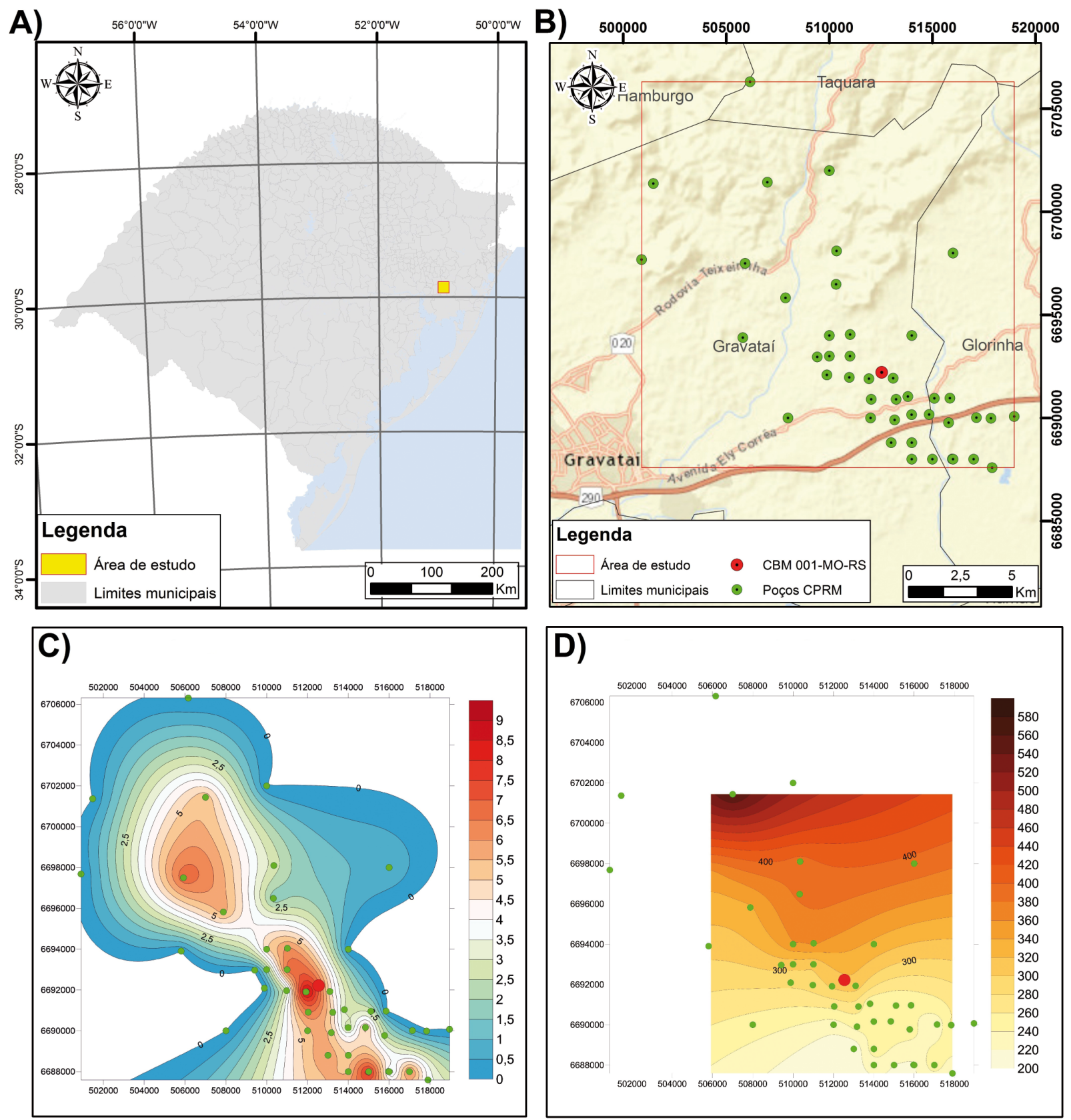

\section{D)}

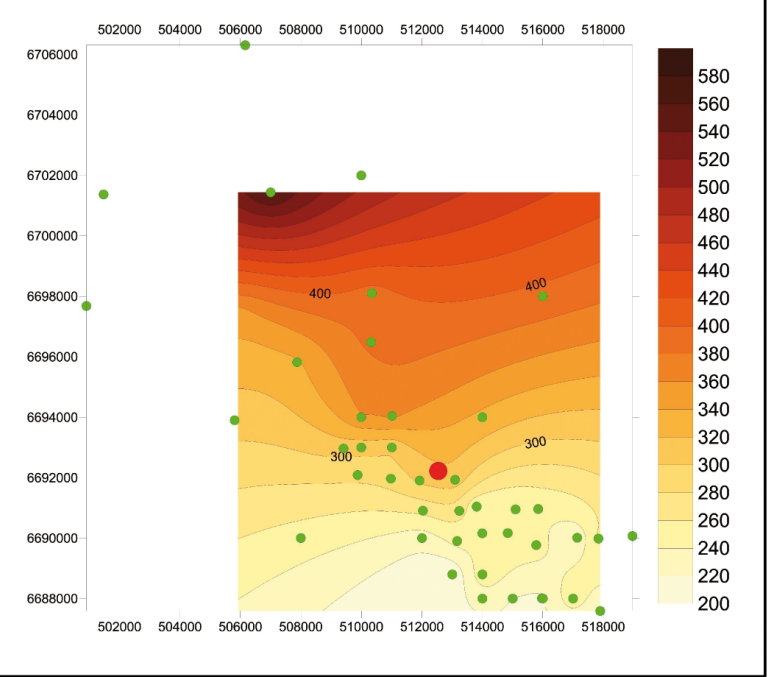

Figura 3. Mapa de localização da área de estudo. A) Área de estudo em relação ao estado do Rio Grande do Sul; B) Locação dos poços da CPRM (verde) utilizados para compor o banco de dados do modelamento e em vermelho a locação do poço CBM 001-MO-RS; C) Mapa de isolinhas da espessura cumulativa de carvão; e D) Mapa de isolinhas da profundidade de aparecimento da primeira camada de carvão.

Figure 3. Location map of the study area: A) Study area in relation to Rio Grande do Sul State; B) Location of boreholes drilled by CPRM (green) which were used to compose the database modeling, and in red the borehole location CBM 001-MO-RS; C) a map of isolines indicating cumulative thickness of coal; and D) a map of isolines indicating the depth of the first coalbed in the study area.

norma NBR 8628 (ABNT, 1984) e expressado em $\mathrm{Kcal} / \mathrm{Kg}$. $\mathrm{O}$ termo poder calorífico superior se refere a um resultado em base úmida e incluída a cinza. Tendo em vista que a norma adotada neste estudo (UN, 1998) utiliza como unidade de poder calorífico $\mathrm{MJ} / \mathrm{Kg}$ em base úmida e livre de cinza, para as 27 amostras foram realizadas conversões e os valores estão retratados em ambas às unidades.

Para identificação das fases minerais conti- das na fração inorgânica, foi utilizado o método de Difratometria de Raios-X, o qual consiste no scaneamento de amostras pulverizadas em granulometria menor que 200 mesh. Neste método, um composto pode ser identificado comparando-se os espaçamentos interplanares e as intensidades dos picos da amostra com os padrões de DRX (banco de dados). 
Quadro 1. Classificação dos litotipos (Stopes, 1919; Diessel, 1965).

Chart. Lithotypes classification (Stopes, 1919; Diessel, 1965).

\begin{tabular}{|c|c|c|}
\hline Stopes & Diessel (1965) & Descrição \\
\hline Vitrênio & Brilhante (B) & $\begin{array}{l}\text { Brilho vítreo a subvítreo, fratura conchoidal; frágil; } \\
\text { até } 10 \% \text { de bandas de carvão fosco. }\end{array}$ \\
\hline \multirow{2}{*}{ Clarênio } & Bandado Brilhante (BB) & $\begin{array}{l}\text { Brilhante, com bandas de carvão fosco que podem } \\
\text { variar entre } 10-40 \% \text {. }\end{array}$ \\
\hline & Carvão Bandado (BC) & $\begin{array}{l}\text { Bandas de carvão brilhante e fosco que variam } \\
\text { entre } 40 \text { e } 60 \% \text {. }\end{array}$ \\
\hline \multirow{2}{*}{ Durênio } & Carvão Fosco Bandado (BD) & $\begin{array}{l}\text { Predomínio de carvão fosco com bandas de carvão } \\
\text { brilhante em proporções entre } 10 \text { a } 40 \% \text {. }\end{array}$ \\
\hline & Carvão Fosco (D) & $\begin{array}{l}\text { Fosco e não fraturado, podendo conter até } 10 \% \text { de } \\
\text { carvão brilhante. }\end{array}$ \\
\hline Fusênio & Carvão Fibroso (F) & Friável. \\
\hline
\end{tabular}

\subsubsection{Ensaios de beneficiamento gravimétrico (afun- da-flutua)}

Os testes de beneficiamento são normalmente realizados por ensaios de afunda-flutua, utilizando-se uma série de diferentes níveis de densidade. Estes ajudam a estimar a separabilidade da matéria orgânica do carvão no processo de concentração por gravidade (Simão \& Kalkreuth, 2015), cabendo mencionar que para tanto foram individualizadas 6 amostras das camadas de carvão (B, C, D, E, F superior e F inferior), respeitando-se a correlação de camadas apresentada na figura 4B.

As amostras das camadas de carvão foram submetidas a ensaios de afunda-flutua em líquidos densos, os quais foram obtidos através de misturas entre xilol, percloroetileno e bromofórmio, fornecendo as densidades de corte 1,5, 1,6 e 2,0 g/ $\mathrm{cm}^{3}$. A aplicação das amostras em tais líquidos produziu como resultado a separação do carvão em frações densimétricas distintas. Para os ensaios, utilizou-se uma granulometria no intervalo de 12,8-1,0 mm, segundo a NBR 8738 (ABNT, 1985). As frações densimétricas resultantes do processo foram submetidas a análises imediatas, determinação do poder calorífico e do rank do carvão através de medidas do poder refletor da vitrinita.

\section{Resultados e discussões}

\subsection{Descrição litológica do poço CBM 001-MO-RS}

A perfuração, ao longo de seu desenvolvimento exploratório, interceptou, inicialmente, sedimentos inconsolidados recentes por aproxima- damente 30 m (Fig. 4A). Após essa profundidade, atingiu-se o substrato rochoso, constituído na área pelas formações Botucatu, Rio do Rasto, Estrada Nova, Irati, Palermo e Rio Bonito. As litologias associadas à Formação Rio Bonito foram localizadas a partir da profundidade de 300,00 m, estendendo-se até a profundidade de $385,76 \mathrm{~m}$, onde encontravam-se em contato direto sobre o embasamento cristalino (Fig. 4A). Ao longo da perfuração foram detectados cinco corpos rochosos oriundos de intrusões ígneas, um deles muito próxima ao intervalo carbonoso, entre as profundidades 312,60 e 331,82 m. Este pacote ígneo intrusivo foi descrito macroscopicamente como uma rocha de coloração escura, apresentando aspecto equigranular fino, com cristais de plagioclásio envoltos em matriz afanítica escura, identificando a rocha como diabásio. Devido à sondagem tratar-se de uma amostragem pontual, fica inviabilizada a determinação da geometria de tal pacote magmático.

Foram identificadas cinco camadas de carvão e um leito carbonoso, definido como tal por apresentar espessura inferior a $20 \mathrm{~cm}$ (Fig. 4B). Destes intervalos obtiveram-se as 27 amostras (Fig. 4C). A identificação das amostras, profundidades de topo e base, espessura e a nomenclatura das camadas encontram-se descritas na tabela 1.

\subsection{Descrição de litotipos}

Considerando-se a descrição macroscópica, ao longo de todo o intervalo carbonoso (Fig. 5), carvão fosco (D) com 34,1\% foi o litotipo predominante, seguido dos litotipos carvão fosco bandado (BD) com $24,3 \%$, carvão bandado (BC) com $16,5 \%$, 


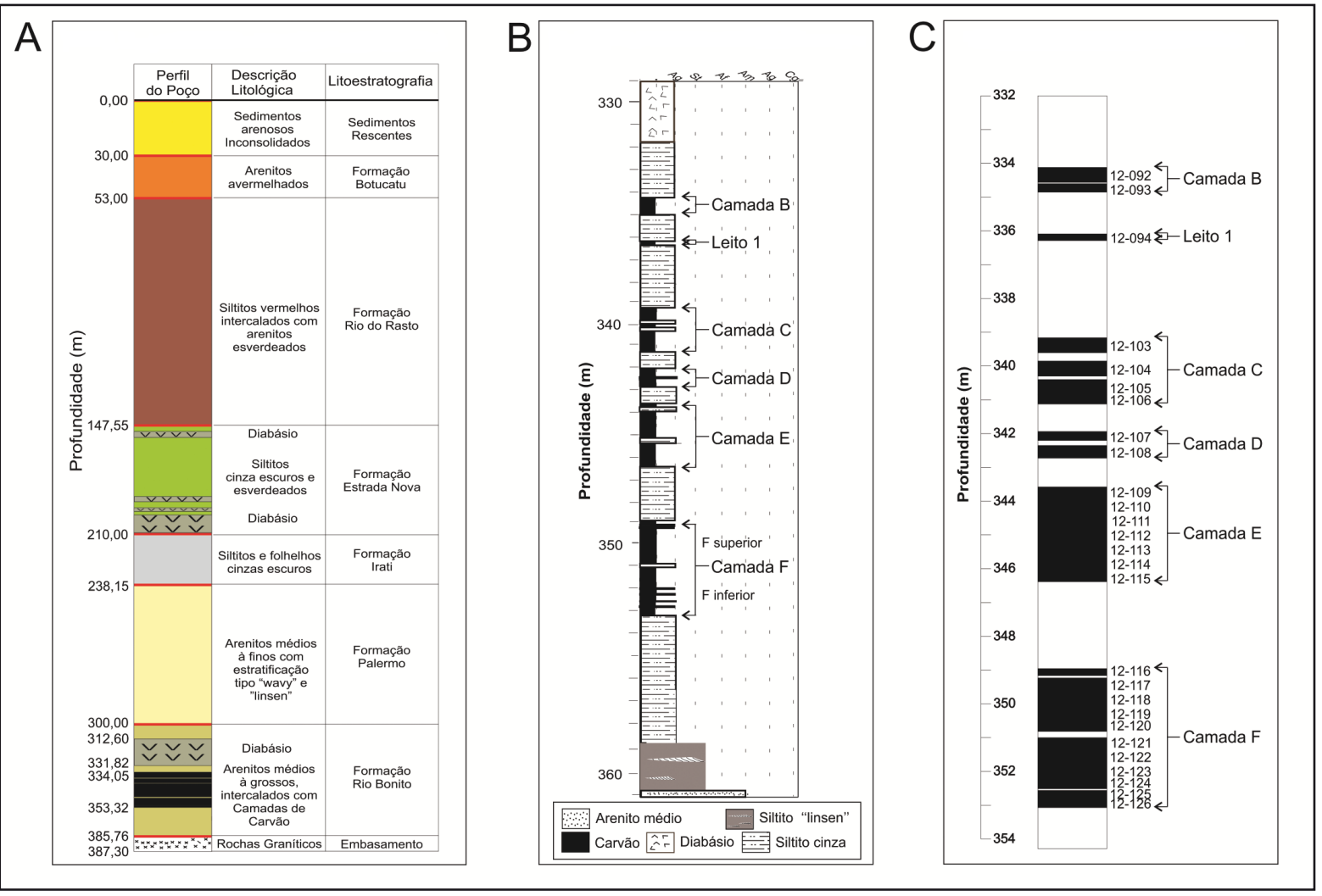

Figura 4. Perfil litológico da sondagem CBM 001-MO-RS. A) Perfil esquemático descritivo do poço exploratório CBM 001-MO-RS; B) Detalhe do intervalo carbonoso; C) Perfil esquemático de detalhe do intervalo carbonoso, indicando os intervalos amostrados.

Figure 4. Lithological profile of borehole CBM 001-MO-RS: A) Schematic profile of borehole CBM 001-MO-RS; B) Detail of coal bearing interval; $C$ ) - Schematic profile with details of the coal-bearing interval such sampled intervals.

Tabela 1. Identificação das amostras, profundidade (topo e base), espessura das amostras coletadas e respectiva identificação. Table 1. Identification of the samples, depth (top and base), and thickness of the samples collected and their respective identification.

\begin{tabular}{|c|c|c|c|c|c|}
\hline \multirow{2}{*}{ Camada } & \multirow{2}{*}{ Amostras } & \multicolumn{2}{|c|}{ Profundidade } & \multirow{2}{*}{ Espessura (m) } & \multirow{2}{*}{ Espessura Total (m) } \\
\hline & & Topo (m) & Base $(\mathrm{m})$ & & \\
\hline \multirow{2}{*}{ B } & $12-092$ & 334,12 & 334,56 & 0,44 & \multirow{2}{*}{0,69} \\
\hline & $12-093$ & 334,60 & 334,85 & 0,25 & \\
\hline L1 & $12-094$ & 336,09 & 336,27 & 0,18 & 0,18 \\
\hline \multirow{4}{*}{$\mathrm{C}$} & $12-103$ & 339,16 & 339,61 & 0,45 & \multirow{4}{*}{1,63} \\
\hline & $12-104$ & 339,85 & 340,30 & 0,45 & \\
\hline & $12-105$ & 340,40 & 340,85 & 0,45 & \\
\hline & $12-106$ & 340,85 & 341,13 & 0,28 & \\
\hline \multirow{2}{*}{ D } & $12-107$ & 341,93 & 342,20 & 0,27 & \multirow{2}{*}{0,66} \\
\hline & $12-108$ & 342,35 & 342,74 & 0,39 & \\
\hline \multirow{7}{*}{$\mathrm{E}$} & $12-109$ & 343,57 & 344,02 & 0,45 & \multirow{7}{*}{2,81} \\
\hline & $12-110$ & 344,02 & 344,24 & 0,22 & \\
\hline & $12-111$ & 344,24 & 344,47 & 0,23 & \\
\hline & $12-112$ & 344,47 & 344,92 & 0,45 & \\
\hline & $12-113$ & 344,92 & 345,38 & 0,46 & \\
\hline & $12-114$ & 345,38 & 345,88 & 0,50 & \\
\hline & $12-115$ & 345,88 & 346,38 & 0,50 & \\
\hline \multirow{11}{*}{$\mathrm{F}$} & $12-116$ & 348,96 & 349,16 & 0,20 & \multirow{11}{*}{3,80} \\
\hline & $12-117$ & 349,23 & 349,68 & 0,45 & \\
\hline & $12-118$ & 349,68 & 350,05 & 0,37 & \\
\hline & $12-119$ & 350,05 & 350,42 & 0,37 & \\
\hline & $12-120$ & 350,42 & 350,81 & 0,39 & \\
\hline & $12-121$ & 350,99 & 351,33 & 0,34 & \\
\hline & $12-122$ & 351,33 & 351,67 & 0,34 & \\
\hline & $12-123$ & 351,67 & 352,12 & 0,45 & \\
\hline & $12-124$ & 352,12 & 352,51 & 0,39 & \\
\hline & $12-125$ & 352,57 & 352,82 & 0,25 & \\
\hline & $12-126$ & 352,82 & 353,07 & 0,25 & \\
\hline
\end{tabular}


carvão bandado brilhante (BB) com 9,3\% e carvão brilhante (B), com apenas 0,3\%. Faz-se importante destacar a presença significativa de siltitos, representando $15,1 \%$ do perfil das amostras, assim como de pirita, com uma presença de 0,4\% (Fig. 5). As camadas de carvão em alguns casos apresentam lâminas de pirita milimétricas as quais não foram passíveis de representação na figura 5 , assim como fraturas preenchidas por carbonato, o qual ocorre mais significativamente nas porções superiores do perfil carbonoso.

\subsection{Refletância da vitrinita}

Os valores de refletância da vitrinita mostram uma grande variação ao longo do intervalo carbonoso, desde $0,61 \mathrm{Rr} \%$ na amostra basal da camada F, até um valor de 4,52 Rr\% na amostra L1 (Tab.
2). Observa-se um aumento progressivo dos valores de refletância da vitrinita no sentido da base para o topo do perfil, aumento que apresenta uma alta correlação de incremento exponencial (Fig. 6). Este fenômeno se justifica pela presença de uma intrusão vulcânica, localizada acima do intervalo carbonoso (Fig. 4A e 4B).

Todas as camadas mostram uma significativa variação em nível da refletância, mostrando um decréscimo dos valores do topo para a base das camadas como consequência da intrusão vulcânica sobreposta (Tab. 2).

Segundo Thomaz-Filho et al. (2008), o efeito de intrusões nas rochas encaixantes é equivalente a espessura do corpo intrusivo. Esse processo pode sofrer alterações em função da profundidade em que se implantou a intrusão, sendo maior o calor transmitido quando as rochas encontram-se

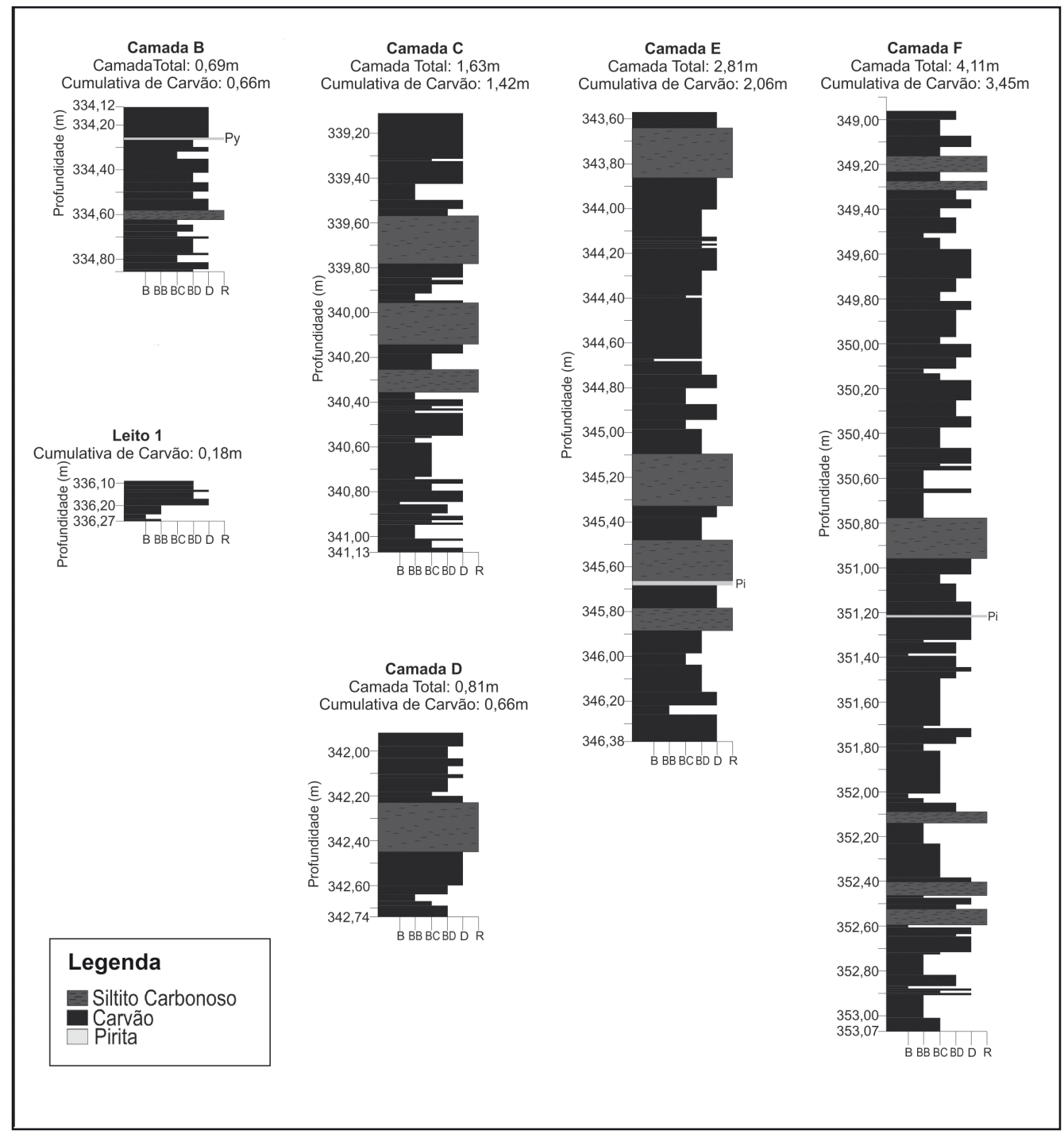

Figura 5. Descrição dos litotipos de carvão no poço exploratório CBM 001-MO-RS de acordo com o esquema de classificação simplificada de Diessel (1965). B - brilhante; BB - bandado brilhante; BC - carvão bandado; BD - carvão fosco bandado; D carvão fosco; R - rocha.

Figure 5. Description of coal lithotypes in exploration borehole CBM 001-MO-RS according to the simplified classification scheme by Diessel (1965). B- bright, BB- banded bright, BC-banded coal, BD-banded dull, D-dull. 
Tabela 2. Identificação das camadas e suas respectivas amostras com resultados das medições de reflectância da vitrinita das amostras de carvão analisadas. $\operatorname{Rr}(\%)$ : Rrandom (\%); Rr (\%) variação: Rrandom (\%) máximo e mínimo por camada de carvão, $\operatorname{Rr}(\%)$ médio: reflectância média calcula para camada.

Table 2. Identification of coal seams and their respective samples, with results of vitrinite reflectance measurements of the coal samples analyzed. $\operatorname{Rr}(\%)$ : Rrandom (\%); $\operatorname{Rr}(\%)$ range: Rrandom (\%) minimum and maximum for the coal seams, $\operatorname{Rr}(\%)$ medium: calculated average reflectance level for each coal seam.

\begin{tabular}{|c|c|c|c|c|c|}
\hline Camadas & Amostras & $\operatorname{Rr}(\%)$ & Grau de carbonificação (rank) & $\operatorname{Rr}(\%)$ variação & $\begin{array}{l}\operatorname{Rr}(\%) \\
\text { médio }\end{array}$ \\
\hline \multirow{2}{*}{$\mathrm{B}$} & $12-092$ & 4,42 & Antracito & \multirow{2}{*}{$4,42-4,32$} & \multirow{2}{*}{4,384} \\
\hline & $12-093$ & 4,32 & Antracito & & \\
\hline L1 & $12-094$ & 4,52 & Antracito & 4,52 & 4,520 \\
\hline \multirow{4}{*}{$\mathrm{C}$} & $12-103$ & 4,00 & Antracito & \multirow{4}{*}{$4,00-2,89$} & \multirow{4}{*}{3,480} \\
\hline & $12-104$ & 3,62 & Antracito & & \\
\hline & $12-105$ & 3,19 & Antracito & & \\
\hline & $12-106$ & 2,89 & Semi Antracito & & \\
\hline \multirow{2}{*}{$\mathrm{D}$} & $12-107$ & 2,67 & Semi Antracito & \multirow{2}{*}{$2,67-2,44$} & \multirow{2}{*}{2,537} \\
\hline & $12-108$ & 2,44 & Semi Antracito & & \\
\hline \multirow{7}{*}{$\mathrm{E}$} & $12-109$ & 2,20 & Semi Antracito & \multirow{7}{*}{$2,20-1,54$} & \multirow{7}{*}{1,818} \\
\hline & $12-110$ & 2,11 & Semi Antracito & & \\
\hline & $12-111$ & 1,87 & Betuminoso Baixo Volátil & & \\
\hline & $12-112$ & 1,84 & Betuminoso Baixo Volátil & & \\
\hline & $12-113$ & 1,77 & Betuminoso Baixo Volátil & & \\
\hline & $12-114$ & 1,63 & Betuminoso Baixo Volátil & & \\
\hline & $12-115$ & 1,54 & Betuminoso Baixo Volátil & & \\
\hline \multirow{11}{*}{$\mathrm{F}$} & $12-116$ & 1,31 & Betuminoso Médio Volátil & \multirow{11}{*}{$1,31-0,61$} & \multirow{11}{*}{0,995} \\
\hline & $12-117$ & 1,27 & Betuminoso Médio Volátil & & \\
\hline & $12-118$ & 1,18 & Betuminoso Médio Volátil & & \\
\hline & $12-119$ & 1,07 & Betuminoso Alto Volátil A & & \\
\hline & $12-120$ & 0,97 & Betuminoso Alto Volátil A & & \\
\hline & $12-121$ & 0,87 & Betuminoso Alto Volátil A & & \\
\hline & $12-122$ & 0,78 & Betuminoso Alto Volátil A & & \\
\hline & $12-123$ & 0,73 & Betuminoso Alto Volátil A & & \\
\hline & $12-124$ & 0,70 & Betuminoso Alto Volátil B & & \\
\hline & $12-125$ & 0,71 & Betuminoso Alto Volátil B & & \\
\hline & $12-126$ & 0,61 & Betuminoso Alto Volátil B & & \\
\hline
\end{tabular}

em maior profundidade. Levandowski (2013), trabalhando na Jazida de Chico-Lomã, encontrou uma relação de equivalência entre a espessura da intrusão vulcânica e a espessura de intervalo carbonoso afetado.

No que concerne ao poço exploratório CBM 001-MO-RS, a intrusão vulcânica sotoposta ao intervalo carbonoso apresenta uma espessura de 19,11 m, a qual gerou uma auréola de influência térmica que atinge, em diferentes níveis, toda a plenitude do intervalo carbonoso de 19,47 m (Fig. 6), corroborando a relação de equivalência entre espessura da intrusão e intervalo carbonoso afetado preconizado por Thomaz-Filho et al. (2008) e Levandowski (2013).

Os valores de refletância da vitrinita das 27 amostras são apresentados na tabela 2, assim como o respectivo grau de carbonificação (rank) conforme classificação ISO (2009a: 7404-3).

\subsection{Análise de macerais}

$\mathrm{Na}$ análise quantitativa dos constituintes microscópicos das amostras, o grupo da vitrinita apresenta uma amplitude de ocorrência de 0,2 a $62,8 \%$ (Tab. 3), liptinita exibe uma variação de 0,0 a 4,0 \% e inertinita mostra uma variação de 12,2 a $38,6 \%$. A matéria mineral determinada na análise petrográfica exibe um range de 17,4 a 81,0 \% (Tab. $3)$. Dentre os constituintes da matéria mineral, os argilomineirais são os mais abundantes, com valores variando de $11,6 \%$ a $73,2 \%$ e, secundaria- 


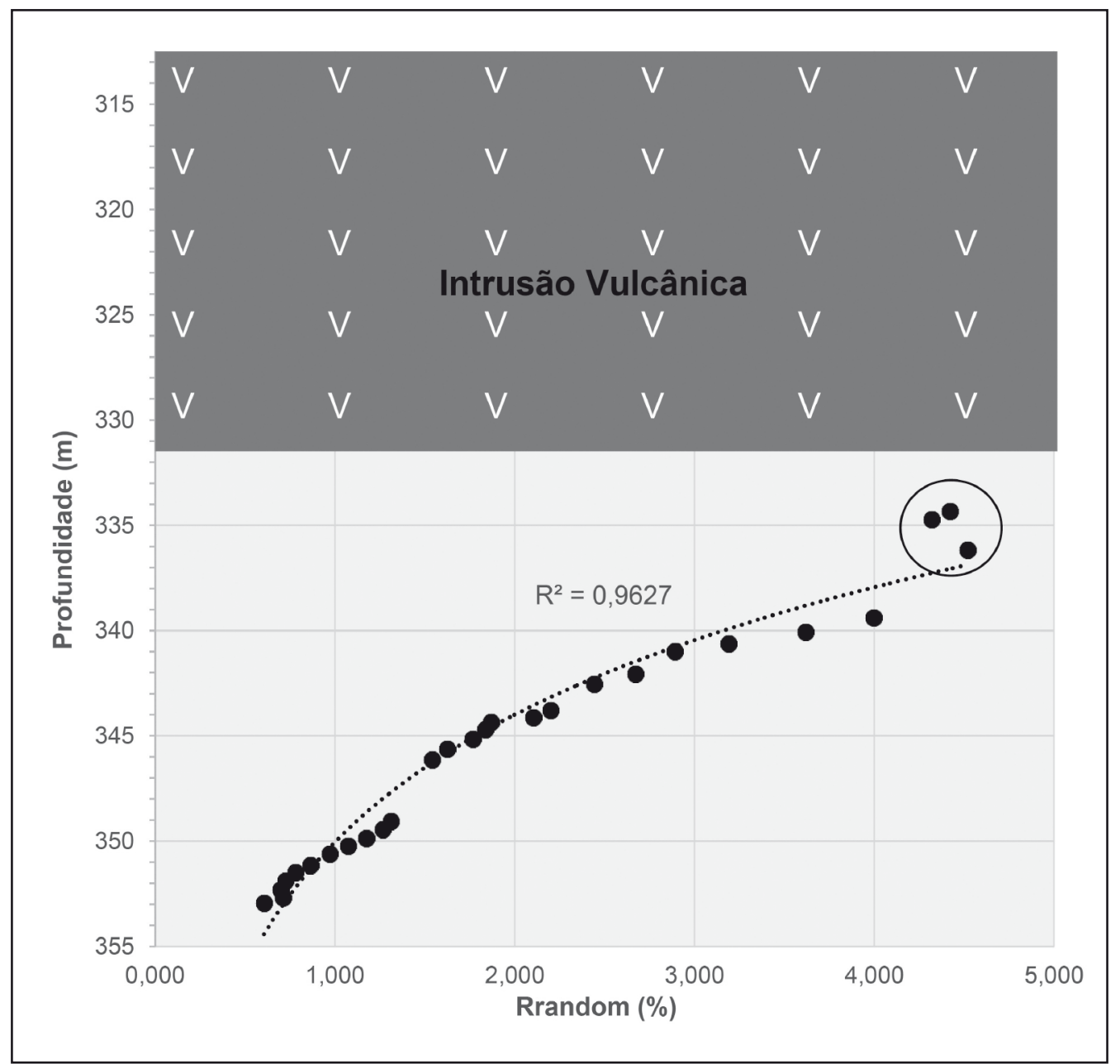

Figura 6. Relação entre valores de refletância da vitrinita e a profundidade das amostras. Círculo preto indicando as amostras que coque natural foi observado. A linha tracejada preta representa a linha de tendência exponencial com um coeficiente de correlação de $\mathrm{R}^{2}=0,957$.

Figure 6. Relationship between vitrinite reflectances values and sample depth. Black circles indicate samples were natural coke was observed. The black dashed line represents the exponential trendline, with a correlation coefficient of $R^{2}=0.957$.

mente, registra-se a ocorrência de quartzo, pirita e carbonato. Convém salientar a presença de coque natural nas amostras 12-092, 12-093 e 12-094, com teores indo de 0,2 a 2,0 \% (Tab. 3).

Conforme mostra a figura 7 (na porção superior do intervalo carbonoso), ocorre predomínio de inertinita, já na porção inferior, composta pela camada F, há predomínio do maceral vitrinita. Vitrinita aponta para a camada $\mathrm{F}$ uma tendência de aumento do seu volume no sentido topo para base da camada, comportamento inverso ao do grupo maceral inertinita para a mesma camada.

0 grupo da liptinita ocorre de forma significativa somente na camada F. Segundo Mastalerz et al. (2009), a liptinita sofre desvolatilização em temperaturas superiores a $300^{\circ} \mathrm{C}$, o que pode indicar que a ausência deste maceral na porção superior do intervalo tenha relação com temperaturas superiores a $300^{\circ} \mathrm{C}$. Na porção superior do perfil, a liptinita foi identificada por sua morfologia, não exibindo a típica fluorescência devido ao efeito térmico causada pela intrusão.

0 conteúdo de matéria mineral caracteriza-se por ser elevado (Tab. 3), apresentando uma leve tendência de aumento da base para o topo do intervalo carbonoso, em uma relação inversamente proporcional aos volumes de inertinita e vitrinita (Fig. 7). 0 conteúdo de matéria mineral na camada F tem um comportamento que se assemelha ao comportamento dos teores de pirita e de liptinita, com valores mais elevados na base e no topo da camada (Fig. 7), reduzindo-se gradativamente em direção à porção intermediária. Este comportamento, na porção pouco afetada termicamente do perfil (camada F), pode estar relacionado a pulsos transgressivos-regressivos que causaram entrada 
de água salina e sedimentos siliciclásticos no ambiente de turfeira. Nas porções mais próximas à intrusão, o efeito térmico causado pela mesma pode ter mascarado tais informações.

A pirita é identificada somente na porção inferior do intervalo carbonoso, sendo observada até a camada D. Na porção superior e mais próxima a intrusão, sua ausência pode ter relação com a influência térmica causada pela intrusão, dada a baixa temperatura de volatilização de tal mineral.

A composição petrográfica no que se refere aos grupos macerais (vitrinita + liptinita + iner- tinita $=100 \%$ ) nas 27 amostras de carvão é altamente variável, oscilando com valores de 0,9 a $79,9 \%$ no grupo maceral vitrinita, 17,2 a $99,1 \%$ no grupo maceral inertinita e 0,0 a $10,2 \%$ para o grupo maceral liptinita (Tab. 4).

Dentro do grupo vitrinita predominam os macerais colotelinita e colodetrinita; dentro do grupo liptinita predominam os macerais liptodetrinita e esporinita e dentro do grupo da inertinita predominam os macerais inertodetrinita e fusinita (Tab. $3)$.

Tabela 3. Resultados das análises de macerais, que mostram a composição maceral e mineral e a composição maceral, recalculada numa base livre de matéria mineral para cada amostra e cálculo por camada. Total:matéria mineral inclusa; s/mm: sem matéria mineral.

Table 3. Results from maceral analyses showing maceral and mineral composition and maceral composition recalculated mineral matter-free basis for each sample and recalculation for each coal seam. Total: mineral matter included; S/MM: mineral matter-free.

\begin{tabular}{|c|c|c|c|c|c|c|c|c|c|c|c|c|c|}
\hline \multirow{2}{*}{ Camada } & \multirow{2}{*}{ Amostra } & \multicolumn{2}{|c|}{ Vitrinita } & \multicolumn{2}{|c|}{ Liptinita } & \multicolumn{2}{|c|}{ Inertinita } & \multicolumn{2}{|c|}{ Coque } & \multicolumn{4}{|c|}{ Matéria Mineral } \\
\hline & & Tot. & $\mathrm{s} / \mathrm{mm}$ & Tot. & $\mathrm{s} / \mathrm{mm}$ & Tot. & $\mathrm{s} / \mathrm{mm}$ & Tot. & $\mathrm{s} / \mathrm{mm}$ & Arg & Qtz & Pir & Carb \\
\hline \multirow{3}{*}{ B } & $12-092$ & 19,6 & 41,7 & 0,0 & 0,0 & 25,4 & 54,0 & 2,0 & 4,3 & 47,6 & 1,8 & 0,0 & 3,6 \\
\hline & $12-093$ & 21,4 & 41,6 & 0,0 & 0,0 & 28,4 & 55,3 & 1,6 & 3,1 & 40,8 & 3,2 & 0,0 & 4,6 \\
\hline & Cam.* & 20,3 & 41,7 & 0,0 & 0,0 & 26,5 & 54,5 & 1,9 & 3,8 & 45,1 & 2,3 & 0,0 & 4,0 \\
\hline L1 & $12-094$ & 22,8 & 50,2 & 0,0 & 0,0 & 22,4 & 49,3 & 0,2 & 0,4 & 45,2 & 3,2 & 0,0 & 6,2 \\
\hline \multirow{5}{*}{$\mathrm{C}$} & $12-103$ & 12,6 & 27,9 & 0,8 & 1,8 & 31,8 & 70,4 & 0,0 & 0,0 & 45,0 & 7,0 & 0,0 & 2,8 \\
\hline & $12-104$ & 15,8 & 34,5 & 0,4 & 0,9 & 29,6 & 64,6 & 0,0 & 0,0 & 49,2 & 3,4 & 0,0 & 1,6 \\
\hline & $12-105$ & 30,4 & 45,2 & 0,0 & 0,0 & 36,8 & 54,8 & 0,0 & 0,0 & 30,0 & 1,4 & 0,0 & 1,4 \\
\hline & $12-106$ & 30,4 & 54,9 & 0,0 & 0,0 & 25,0 & 45,1 & 0,0 & 0,0 & 37,0 & 1,6 & 0,0 & 6,0 \\
\hline & Cam.* & 21,5 & 39,1 & 0,3 & 0,7 & 31,4 & 60,1 & 0,0 & 0,0 & 40,6 & 3,5 & 0,0 & 2,6 \\
\hline \multirow{3}{*}{$\mathrm{D}$} & $12-107$ & 0,2 & 0,9 & 0,0 & 0,0 & 21,4 & 99,1 & 0,0 & 0,0 & 71,6 & 5,4 & 0,0 & 1,4 \\
\hline & $12-108$ & 4,2 & 10,6 & 0,6 & 1,5 & 35,0 & 87,9 & 0,0 & 0,0 & 53,2 & 3,8 & 0,6 & 2,6 \\
\hline & Cam.* & 2,6 & 6,6 & 0,4 & 0,9 & 29,4 & 92,5 & 0,0 & 0,0 & 60,7 & 4,5 & 0,4 & 2,1 \\
\hline \multirow{8}{*}{ E } & $12-109$ & 3,8 & 20,0 & 0,0 & 0,0 & 15,2 & 80,0 & 0,0 & 0,0 & 70,6 & 3,8 & 1,0 & 5,6 \\
\hline & $12-110$ & 9,6 & 20,3 & 0,2 & 0,4 & 37,6 & 79,3 & 0,0 & 0,0 & 47,2 & 4,0 & 0,2 & 1,2 \\
\hline & $12-111$ & 12,4 & 24,1 & 0,4 & 0,8 & 38,6 & 75,1 & 0,0 & 0,0 & 44,0 & 3,6 & 0,0 & 1,0 \\
\hline & $12-112$ & 19,4 & 34,9 & 0,2 & 0,4 & 36,0 & 64,7 & 0,0 & 0,0 & 38,2 & 4,4 & 0,0 & 1,8 \\
\hline & $12-113$ & 10,2 & 23,6 & 0,0 & 0,0 & 33,0 & 76,4 & 0,0 & 0,0 & 51,8 & 2,2 & 0,0 & 2,8 \\
\hline & $12-114$ & 1,2 & 5,5 & 0,0 & 0,0 & 20,6 & 94,5 & 0,0 & 0,0 & 73,2 & 2,0 & 0,0 & 3,0 \\
\hline & $12-115$ & 6,0 & 14,9 & 0,2 & 0,5 & 34,0 & 84,6 & 0,0 & 0,0 & 56,0 & 1,8 & 0,0 & 2,0 \\
\hline & Cam.* & 8,4 & 19,9 & 0,1 & 0,2 & 29,4 & 79,9 & 0,0 & 0,0 & 56,2 & 3,0 & 0,2 & 2,7 \\
\hline \multirow{12}{*}{$\mathrm{F}$} & $12-116$ & 24,8 & 52,1 & 0,0 & 0,0 & 22,8 & 47,9 & 0,0 & 0,0 & 39,2 & 3,4 & 3,6 & 6,2 \\
\hline & $12-117$ & 25,0 & 46,8 & 0,0 & 0,0 & 28,4 & 53,2 & 0,0 & 0,0 & 39,6 & 3,6 & 3,0 & 0,4 \\
\hline & $12-118$ & 13,6 & 34,7 & 4,0 & 10,2 & 21,6 & 55,1 & 0,0 & 0,0 & 55,0 & 4,2 & 0,0 & 1,6 \\
\hline & $12-119$ & 26,0 & 43,0 & 0,0 & 0,0 & 34,4 & 57,0 & 0,0 & 0,0 & 34,2 & 3,0 & 0,6 & 1,8 \\
\hline & $12-120$ & 54,8 & 76,5 & 0,2 & 0,3 & 16,6 & 23,2 & 0,0 & 0,0 & 25,6 & 0,0 & 0,4 & 2,4 \\
\hline & $12-121$ & 54,0 & 68,2 & 1,0 & 1,3 & 24,2 & 30,6 & 0,0 & 0,0 & 14,4 & 0,4 & 0,4 & 5,6 \\
\hline & $12-122$ & 56,4 & 68,3 & 0,8 & 1,0 & 25,4 & 30,8 & 0,0 & 0,0 & 11,6 & 0,6 & 0,2 & 5,0 \\
\hline & $12-123$ & 47,0 & 58,9 & 1,2 & 1,5 & 31,6 & 39,6 & 0,0 & 0,0 & 15,8 & 1,2 & 0,6 & 2,6 \\
\hline & $12-124$ & 62,8 & 79,9 & 0,2 & 0,3 & 15,6 & 19,8 & 0,0 & 0,0 & 18,8 & 0,0 & 0,6 & 2,0 \\
\hline & $12-125$ & 38,4 & 65,1 & 3,6 & 6,1 & 17,0 & 28,8 & 0,0 & 0,0 & 33,8 & 1,8 & 0,8 & 4,6 \\
\hline & $12-126$ & 56,6 & 79,9 & 2,0 & 2,8 & 12,2 & 17,2 & 0,0 & 0,0 & 17,6 & 2,2 & 4,6 & 4,8 \\
\hline & Cam.* & 41,9 & 60,6 & 1,1 & 2,0 & 23,4 & 37,4 & 0,0 & 0,0 & 27,6 & 1,8 & 1,2 & 3,0 \\
\hline \multicolumn{14}{|c|}{$\begin{array}{l}\text { Tot. - Total, s/mm - Sem matéria mineral, valores recalculados livres de material mineral } \\
\text { * Valores médios recalculados para camada total. }\end{array}$} \\
\hline
\end{tabular}




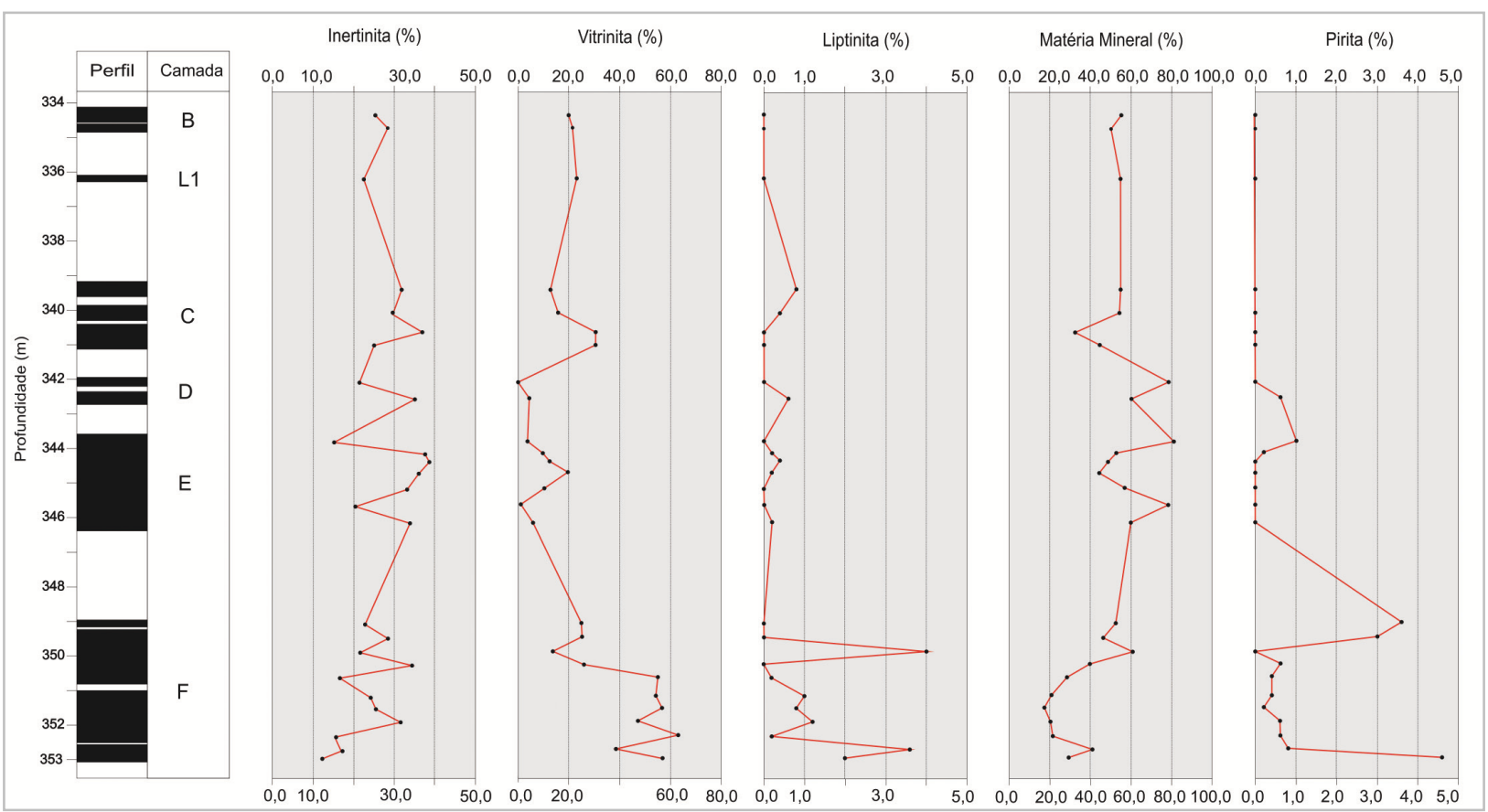

Figura 7. Perfil esquemático mostrando a variação do conteúdo de macerais e matéria mineral (vol.\%) com a profundidade estratigráfica.

Figure 7. Schematic profile showing the variation of the macerals and mineral matter contents (vol. \%) with stratigraphic depth.

\subsection{Análises imediatas e mineralógicas}

Os resultados das análises imediatas, em base seca, estão detalhados na tabela 4.0 teor de cinzas mostrou uma variação dos valores osciulando de 39,66 a $81,82 \%$. Ao recalcular os teores de cinza levando-se em conta as correlações de camada, obteve-se uma variação de valores entre 69,20 \% na camada D e 50,10 \% para a camada F.

Os resultados das análises imediatas, em base seca, estão detalhados na tabela 4. Segundo metodologia proposta pela norma internacional da Comissão Econômica da Europa para as Nações Unidas, 33 \% das amostras do estudo podem ser consideradas como carvão de categoria muito inferior, enquanto $67 \%$ podem ser denominadas de rocha carbonosa. Este enquadramento dos resultados analíticos ante tal classificação pode ser observado na figura $8 \mathrm{~A}$.

Na figura 8B são apresentados os resultados recalculados levando-se em conta a configuração de correlação de camadas totais. Neste contexto, $16,7 \%$ das camadas (camada F) podem ser consideradas como carvão de categoria muito inferior, enquanto 83,3 \% (camadas B, C, D, E e leito 1) podem ser classificados como rocha carbonosa (Tab. 4).

O conteúdo de matéria volátil em base seca apresentou como resultado uma variação de 5,76 a 30,69 \% (Tab. 4), exibindo uma correlação inversa com os valores de refletância da vitrinita na porção preponderante (Fig. 9). As amostras mais próximas à intrusão são as que têm o maior valor de poder refletor (Fig. 6) e os menores valores de matéria volátil. Este conjunto de características está em conformidade com os resultados obtidos por Levandowski (2013) na análise do poço CBM 001-CL-RS, da Jazida de Chico Lomã.

0 teor de enxofre das amostras exibiu como resultado uma variação de 0,20 até 2,88 \% (Tab. 4), com valores mais elevados nas amostras da base do perfil carbonoso. Esta tendência pode sugerir influência marinha nas camadas E e F, porém, faz-se importante destacar a possibilidade de o efeito térmico sobre os carvões ter mascarado essa influência marinha nas camadas superiores.

Em se tratando das análises de poder calorífico superior, uma grande amplitude de valores foi observada nos resultados. 0 menor valor quantificado foi de $777 \mathrm{Kcal} / \mathrm{Kg}(17,9 \mathrm{MJ} / \mathrm{Kg})$. 0 valor mais elevado ficou na ordem de $4.732 \mathrm{Kcal} / \mathrm{Kg}(32,8$ $\mathrm{MJ} / \mathrm{Kg}$ ) (Tab. 4).

Como pode ser visto na figura 10 , existe uma boa correlação estatística entre poder calorífico superior e teor de cinzas, com um coeficiente R próximo a 1,0. A amostra 12-109, que exibiu o menor resultado em valor de poder calorífico, tem o maior conteúdo de cinzas $(81,82 \%)$. Em contrapartida, a amostra 12-120, que apresentou o maior valor de poder calorífico, tem o menor conteúdo de cinzas $(39,66 \%)$ (Tab. 4). 


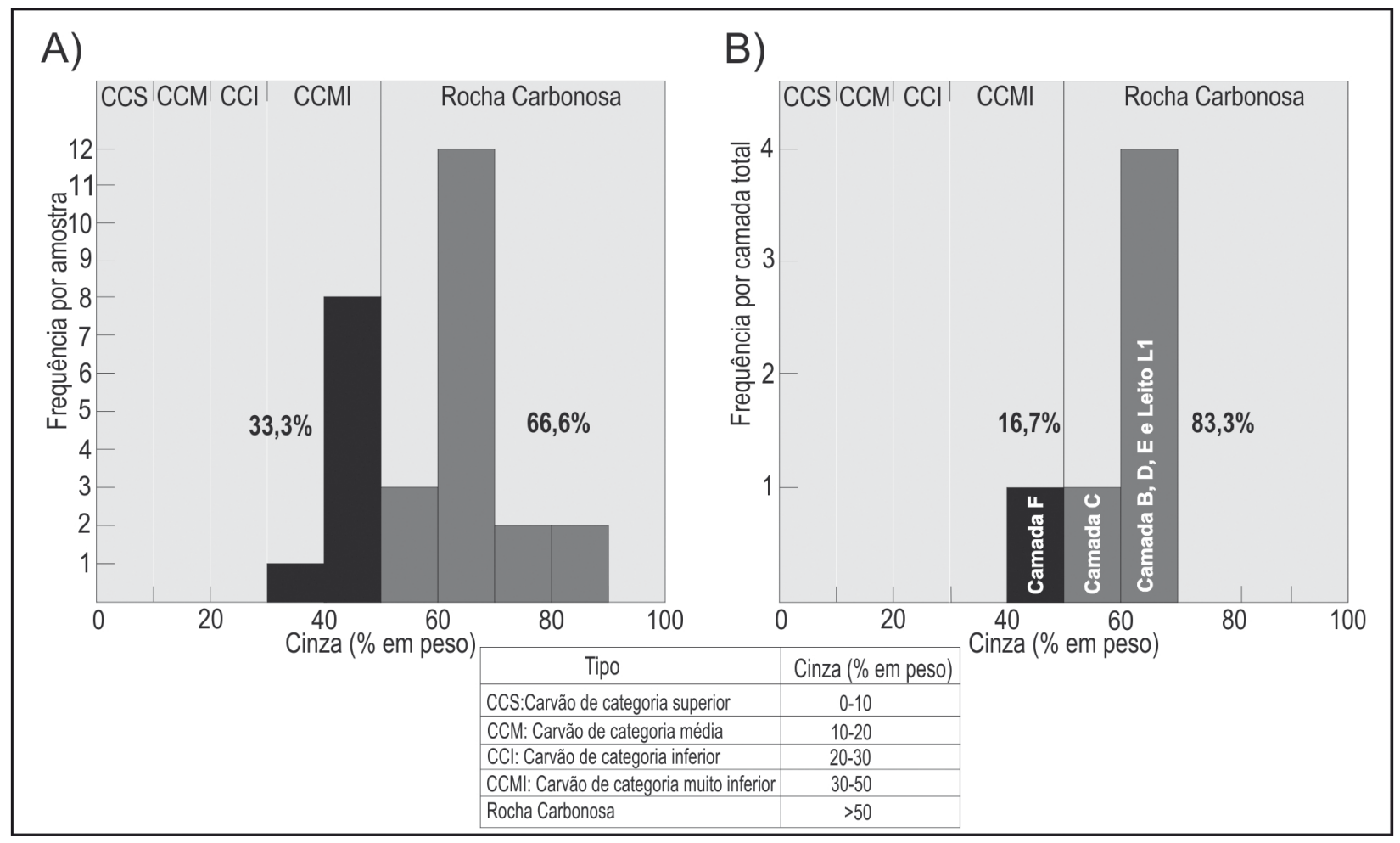

Figura 8. Classificação do carvão segundo o percentual de cinzas. A) Valores das amostras; B) Recalculados para as camadas. Modificado de International Classification of in-coal seams (CEE-UN, 1998).

Figure 8. Coal classification based on ash yields. A) Sample values; B) Calculated values for each coal seam. Modified from International Classification of in- coals seam (CEE-UN, 1998).

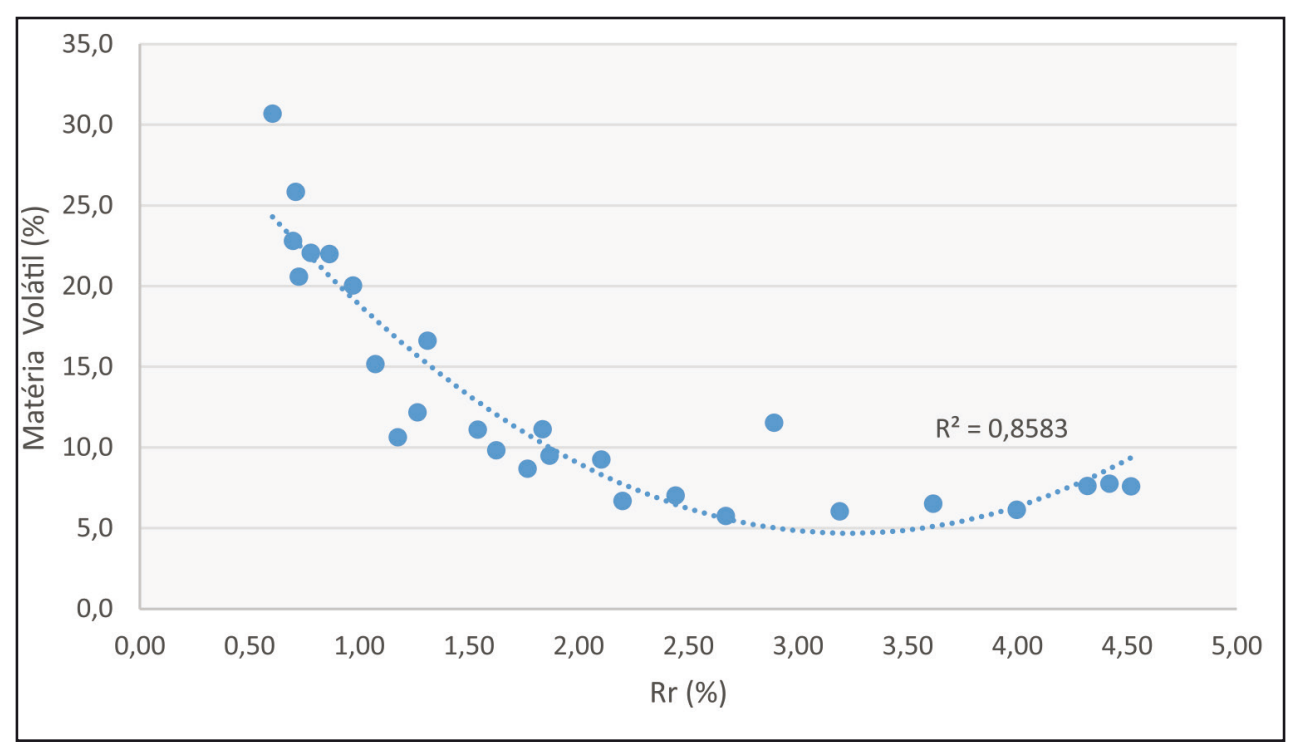

Figura 9. Relação entre o conteúdo de matéria volátil e a refletância da vitrinita para as amostras do poço exploratório CBM 001-MO-RS, mostrando uma linha exponencial de correlação.

Figure 9. Relationship between volatile matter content and vitrinite reflectance for samples from exploration borehole CBM 001-MO-RS, showing an exponential line of correlation. 


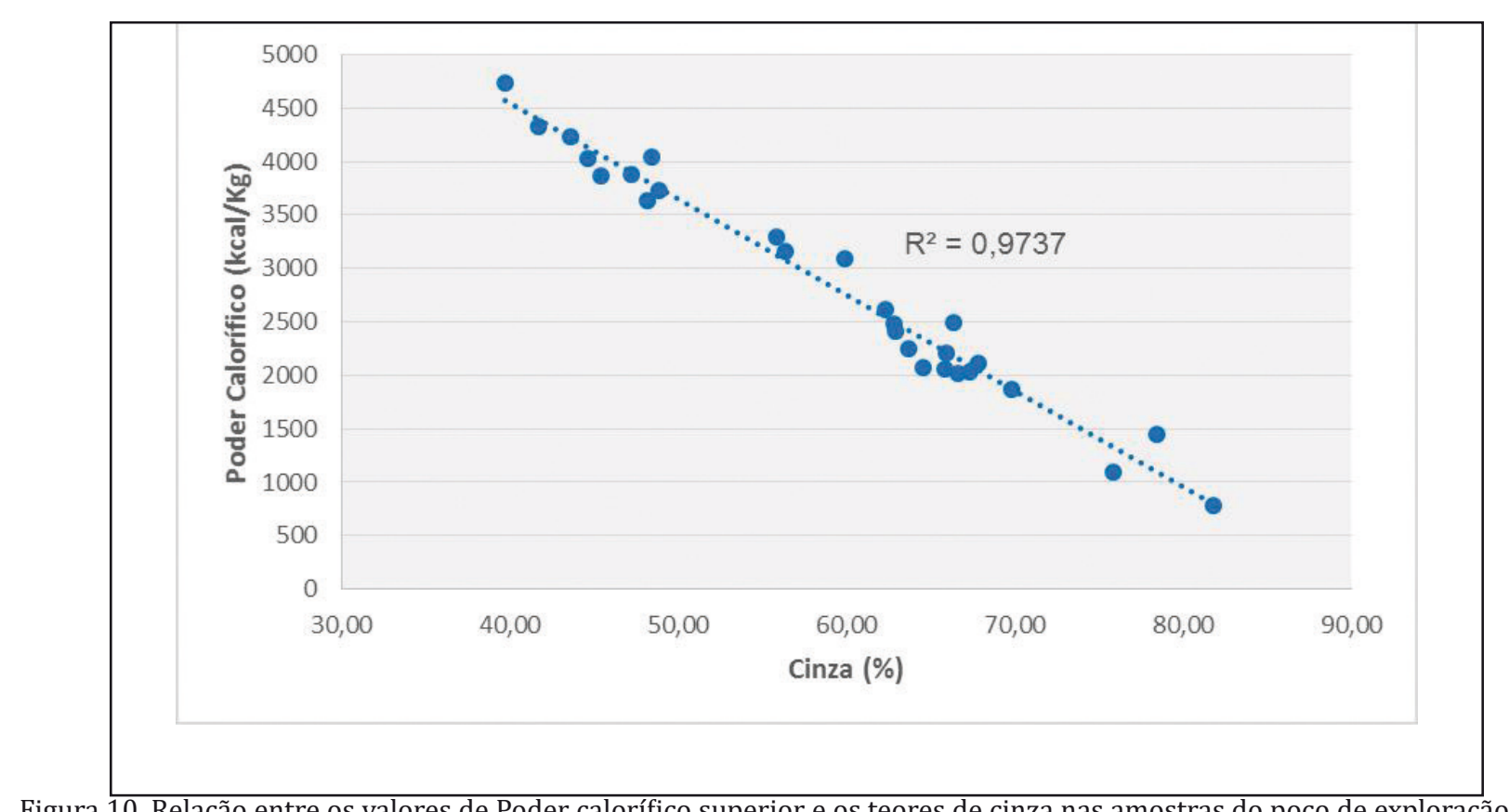

Figura 10. Relação entre os valores de Poder calorífico superior e os teores de cinza nas amostras do poço de exploração CBM 001-MO-RS.

Figure 10. Relationship between Upper calorific values and ash content in samples from exploration borehole CBM 001-MO-RS.

No que concerne à composição mineralógica determinada por meio de difratometria de Raios-X, observou-se um predomínio das fases minerais quartzo, caulinita, illita e plagioclásio. De forma secundária, observou-se ankerita, calcita, dolomita e pirita, encontrados de forma esporádica no conjunto de amostras (Tab. 5).

Os resultados das análises petrográficas e químicas são retratados na figura 11, segundo a configuração da classificação do carvão apresentada pela Comunidade Econômica para Europa, Nações Unidas (UN, 1998). 0 método empregado tem a vantagem de utilizar, de modo simultâneo, os três principais parâmetros empregados na caracterização do carvão (composição, grade e grau de carbonificação ou rank). Os dados das análises necessários para utilização desta metodologia foram apresentados nas tabelas 2 a 4. Cabendo ressalva que utilizou-se para fins de classificação os valores médios calculados para as cinco camadas e um leito carbonoso exibidos no perfil do poço CBM 001-MO-RS.

Seguindo a metodologia classificatória empregada, a camada $\mathrm{F}$ foi classificada como carvão de grau médio $B$, de categoria muito inferior (Fig. 11). As demais camadas foram classificadas respectivamente como: rocha carbonosa de grau superior A para a camada B e Leito 1; rocha carbonosa de grau superior $B$ para a camada $C$ e rocha carbonosa de grau superior C para a camada D. A camada $\mathrm{E}$ foi classificada como rocha carbonosa de grau médio A (Fig. 11).

\subsection{Ensaios de beneficiamento gravimétrico (afun- da-flutua)}

Para fins de caracterização da porção dos testemunhos de sondagem destinada aos ensaios de afunda-flutua, seis amostras correspondentes à camada total de carvão (camadas: B, C, D, E, F superior e $\mathrm{F}$ inferior, fig. 4B) foram analisadas por refletância da vitrinita e análises imediatas (Tab. 6). Nestas amostras foi possível observar que os resultados estão condizentes com os valores médios calculados para as análises de detalhe (Tab. 2 e 4).

Com a realização dos ensaios de afunda-flutua, munidos dos valores de massa das frações afundadas e flutuadas das amostras e dos teores de cinza destas frações (Tab. 8), foram elaboradas as curvas de lavabilidade e densimétrica para as camadas (Fig. 12).

0 mais baixo teor de cinza atingido foi de 6,7 $\%$, obtido na fração com densidade menor de 1,5 $\mathrm{g} / \mathrm{cm}^{3}$ da camada C. Este teor de cinzas foi alcançado a um rendimento de $1,3 \%$ da massa total. 0 valor mais elevado de poder calorífico superior foi de $7.659 \mathrm{Kcal} / \mathrm{Kg}$, nesta mesma amostra (Tab. 7).

Fazendo-se uma análise das curvas de flutuados (Fig. 12A), observa-se que as amostras correspondentes às camadas $\mathrm{F}$ inferior, $\mathrm{F}$ superior $\mathrm{e}$ C são aquelas que demonstraram melhor resposta ao beneficiamento, tendo como resultado um produto de mais baixo teor de cinza e com maior rendimento. A camada com pior resposta ao beneficiamento é a camada $B$, que provavelmente teve 
Tabela 4. Resultados da análise imediata em base seca, enxofre e poder calorífico superior para cada amostra e cálculo para camadas de carvão: Cinzas, \% M.V. - matéria volátil, C.F. - Carbono fixo, S - Enxofre total, PCS - Poder calorífico superior. Table 4. Results of proximate analysis on a dry basis, sulfur and upper calorific values for each sample and recalculation for each coal seam: \% V.M. - volatile matter; F.C. fixed carbon, S - Sulfer, U.C.V. Upper calorific value.

\begin{tabular}{|c|c|c|c|c|c|c|c|}
\hline \multirow[t]{2}{*}{ Camadas } & \multirow[t]{2}{*}{ Amostras } & \multirow{2}{*}{$\frac{\text { Cinzas }}{\left(\% \text { em massa bs. }{ }^{1}\right)}$} & M.V. & C.F. & \multirow{2}{*}{$\frac{\mathbf{S}}{(\% \text { massa })}$} & \multicolumn{2}{|c|}{ PCS } \\
\hline & & & \multicolumn{2}{|c|}{$\%$ massa (bs.sc. ${ }^{2}$ ) } & & (KCal/Kg) & $\left(\mathrm{MJ} / \mathrm{Kg} \mathrm{sc}{ }^{3}\right)$ \\
\hline \multirow{3}{*}{ B } & $12-092$ & 66,36 & 7,76 & 25,88 & 0,41 & 2493 & 31,0 \\
\hline & $12-093$ & 63,64 & 7,61 & 28,75 & 0,67 & 2244 & 25,8 \\
\hline & Camada & 65,37 & 7,71 & 26,92 & 0,50 & 2403 & 29,1 \\
\hline L1 & $12-094$ & 67,82 & 7,59 & 24,59 & 0,45 & 2110 & 27,5 \\
\hline \multirow{5}{*}{$\mathrm{C}$} & $12-103$ & 65,85 & 6,15 & 28,00 & 0,32 & 2055 & 25,2 \\
\hline & $12-104$ & 67,26 & 6,52 & 26,22 & 0,41 & 2029 & 25,9 \\
\hline & $12-105$ & 43,54 & 6,04 & 50,42 & 0,62 & 4228 & 31,4 \\
\hline & $12-106$ & 56,35 & 11,55 & 32,10 & 0,46 & 3154 & 30,3 \\
\hline & Camada & 58,45 & 7,15 & 34,40 & 0,45 & 2837 & 28,6 \\
\hline \multirow{3}{*}{$\mathrm{D}$} & $12-107$ & 78,46 & 5,76 & 15,78 & 0,34 & 1442 & 28,0 \\
\hline & $12-108$ & 62,79 & 7,02 & 30,19 & 0,32 & 2485 & 28,0 \\
\hline & Camada & 69,20 & 6,50 & 24,30 & 0,33 & 2058 & 28,0 \\
\hline \multirow{8}{*}{$\mathrm{E}$} & $12-109$ & 81,82 & 6,70 & 11,48 & 0,80 & 777 & 17,9 \\
\hline & $12-110$ & 66,62 & 9,26 & 24,12 & 0,38 & 2022 & 25,4 \\
\hline & $12-111$ & 62,91 & 9,49 & 27,60 & 0,35 & 2407 & 27,2 \\
\hline & $12-112$ & 59,87 & 11,14 & 28,99 & 2,33 & 3092 & 32,3 \\
\hline & $12-113$ & 62,30 & 8,70 & 29,00 & 0,25 & 2609 & 29,0 \\
\hline & $12-114$ & 75,83 & 9,82 & 14,35 & 0,20 & 1097 & 19,0 \\
\hline & $12-115$ & 65,90 & 11,11 & 22,99 & 0,23 & 2202 & 27,0 \\
\hline & Camada & 68,47 & 9,51 & 22,02 & 0,68 & 1989 & 26,4 \\
\hline \multirow{12}{*}{$\mathrm{F}$} & $12-116$ & 64,55 & 16,63 & 18,82 & 1,66 & 2072 & 24,5 \\
\hline & $12-117$ & 55,85 & 12,18 & 31,97 & 1,16 & 3296 & 31,3 \\
\hline & $12-118$ & 69,78 & 10,65 & 19,57 & 0,27 & 1874 & 26,0 \\
\hline & $12-119$ & 48,38 & 15,18 & 36,44 & 0,63 & 4042 & 32,8 \\
\hline & $12-120$ & 39,66 & 20,06 & 40,28 & 0,61 & 4732 & 32,8 \\
\hline & $12-121$ & 47,21 & 22,00 & 30,79 & 0,67 & 3885 & 30,8 \\
\hline & $12-122$ & 45,36 & 22,07 & 32,57 & 0,62 & 3867 & 29,6 \\
\hline & $12-123$ & 48,12 & 20,60 & 31,28 & 0,82 & 3636 & 29,3 \\
\hline & $12-124$ & 44,61 & 22,80 & 32,59 & 1,13 & 4033 & 30,5 \\
\hline & $12-125$ & 48,80 & 25,84 & 25,36 & 0,92 & 3723 & 30,4 \\
\hline & $12-126$ & 41,71 & 30,69 & 27,60 & 2,88 & 4332 & 31,1 \\
\hline & Camada & 50,10 & 19,33 & 30,57 & 0,95 & 3629 & 30,4 \\
\hline
\end{tabular}

suas características alteradas devido à influência da intrusão vulcânica.

No que concerne às curvas de afundados (Fig. $12 \mathrm{~A})$, nas curvas contidas na figura $12 \mathrm{~A}$ as frações afundadas das amostras exibiram teores de cinza entre 60 a $80 \%$, demonstrando que tais amostras ainda contem de 20 a $40 \%$ de matéria orgânica em sua composição, indicativo de um grau médio de eficiência na liberação entre o carvão e as partículas minerais.

As curvas densimétricas (Fig. 12B) tem como finalidade estimar a densidade do líquido denso a ser empregado para se obter uma separação eficiente entre componentes orgânicos e inorgânicos do carvão. Elas demonstram que as camadas F inferior e F superior têm os menores valores de densidades relativa dentro do conjunto de amostras, em torno de $30 \%$ das partículas exibindo densidade de $1,5 \mathrm{~g} / \mathrm{cm}^{3}$. A camada $\mathrm{C}$ tem uma condição de um pouco superior as anteriores, com $20 \%$ das partículas exibindo densidade de $1,5 \mathrm{~g} / \mathrm{cm}^{3}$. As camadas E e D mostram densidades de partículas mais elevadas, com somente $10 \%$ das partículas exibindo densidade de $1,5 \mathrm{~g} / \mathrm{cm}^{3}$.

De modo geral as curvas densimétricas exibiram uma baixa inclinação da reta, com uma distribuição homogênea de densidade das partículas, fator este que indica uma separabilidade boa, porém, gradativa entre matéria orgânica e inorgânica. A camada B (Fig. 12B) apresentou uma inclinação mais elevada da reta, indicativo de baixa separabilidade entre as densidades 1,6 a 2,0 g/ $\mathrm{cm}^{3}$. 


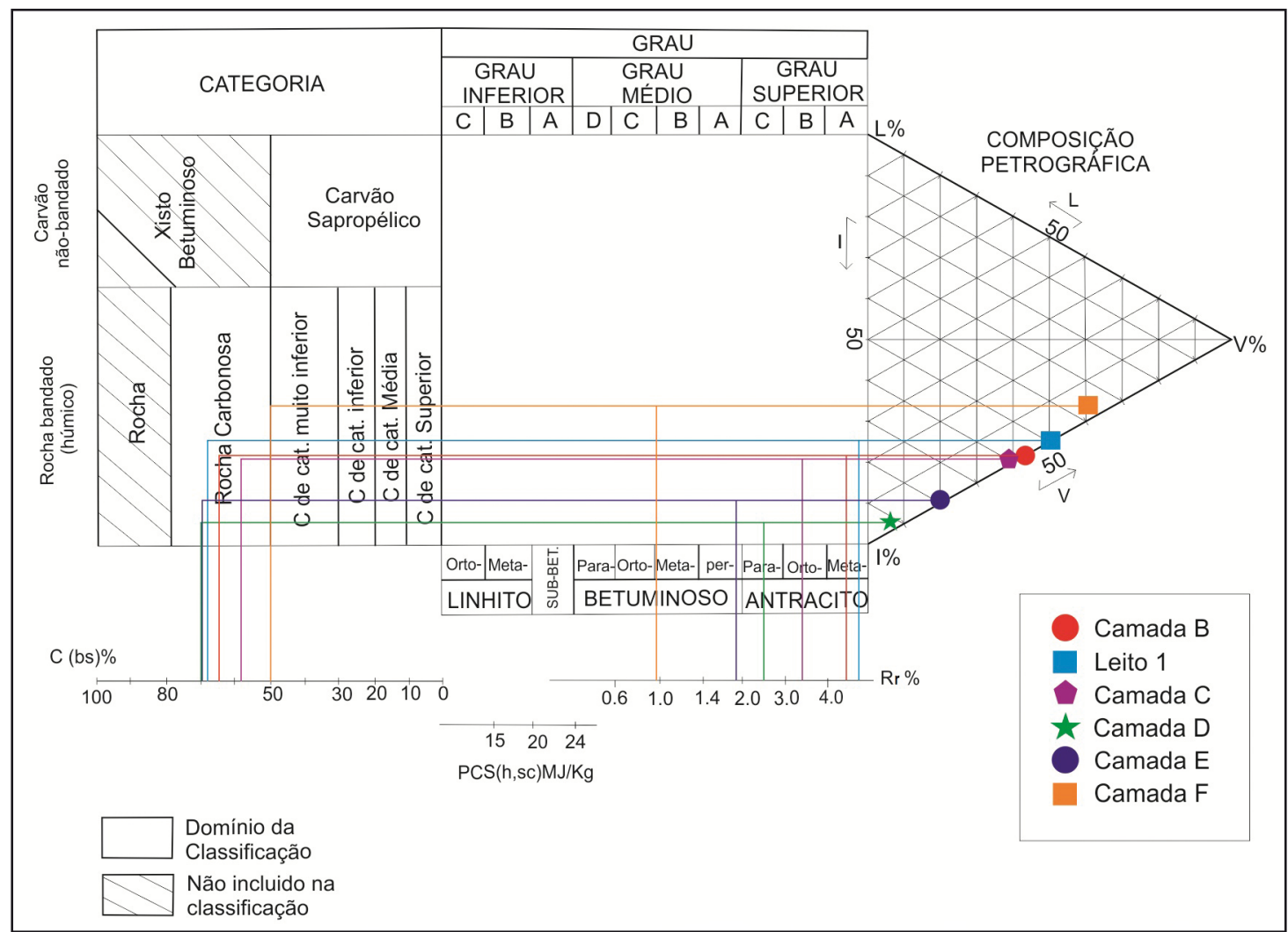

Figura 11. Classificação Internacional das camadas de carvão coletadas no poço de exploração CBM 001-MO-RS da Jazida de Morungava, RS, segundo normas UN (1998). Modificado de Silva (2012).

Figure 11. International Classification of the coal seams collected from exploration borehole CBM 001-MO-RS in the Morungava coalfield based on CEE, UN (1998). Modified from Silva (2012).

Tabela 5. Resultados de difratometria de raios-X para determinação da composição mineral da fração inorgânica do carvão. A presença de minerais na amostra é indicada com X.

Table 5. X-ray diffraction results to determine mineral composition in the inorganic fraction of the coal. Presence of individual minerals in the sample is indicated by $X$.

\begin{tabular}{|c|c|c|c|c|c|c|c|c|c|}
\hline \multirow{2}{*}{ Camadas } & \multirow{2}{*}{ Amostras } & \multicolumn{8}{|c|}{ Minerais (Difratometria de Raios-X) } \\
\hline & & Quartzo & Caulinita & Ilita & Plagioclásio & Ankerita & Calcita & Dolomita & Pirita \\
\hline \multirow{2}{*}{ B } & 12-092 & $\mathrm{X}$ & $\mathrm{X}$ & $\mathrm{X}$ & & $\mathrm{X}$ & & \multirow{3}{*}{$\mathrm{X}$} & \\
\hline & $12-093$ & $\mathrm{X}$ & $X$ & $X$ & & & & & \\
\hline L1 & $12-094$ & $\mathrm{X}$ & $\mathrm{X}$ & & & $\mathrm{X}$ & & & \\
\hline \multirow{4}{*}{$\mathrm{C}$} & $12-103$ & $\mathrm{X}$ & $\mathrm{X}$ & $\mathrm{X}$ & & & & & \\
\hline & $12-104$ & $\mathrm{X}$ & $\mathrm{X}$ & $\mathrm{X}$ & & & & & \\
\hline & $12-105$ & X & $\mathrm{X}$ & $\mathrm{X}$ & $\mathrm{X}$ & $\mathrm{X}$ & & & \\
\hline & $12-106$ & $\mathrm{X}$ & $\mathrm{X}$ & $\mathrm{X}$ & $\mathrm{X}$ & $\mathrm{X}$ & & & \\
\hline \multirow{2}{*}{ D } & $12-107$ & $\mathrm{X}$ & $\mathrm{X}$ & $\mathrm{X}$ & & & & & \\
\hline & $12-108$ & $\mathrm{X}$ & $X$ & & & & & & \\
\hline \multirow{7}{*}{ E } & $12-109$ & X & $\mathrm{X}$ & $X$ & & & & \multirow{7}{*}{$X$} & \\
\hline & $12-110$ & $\mathrm{X}$ & $\mathrm{X}$ & $\mathrm{X}$ & $\mathrm{X}$ & & & & \\
\hline & $12-111$ & $\mathrm{X}$ & $\mathrm{X}$ & $X$ & $\mathrm{X}$ & & & & \\
\hline & $12-112$ & $\mathrm{X}$ & $\mathrm{X}$ & $\mathrm{X}$ & $\mathrm{X}$ & & & & \\
\hline & $12-113$ & $\mathrm{X}$ & $\mathrm{X}$ & $\mathrm{X}$ & & & & & \\
\hline & $12-114$ & $\mathrm{X}$ & $\mathrm{X}$ & $\mathrm{X}$ & & & & & \\
\hline & $12-115$ & X & X & $X$ & X & & & & \\
\hline \multirow{11}{*}{$\mathrm{F}$} & $12-116$ & $\mathrm{X}$ & & $\mathrm{X}$ & & \multirow[t]{4}{*}{$\mathrm{X}$} & \multirow[t]{4}{*}{$\mathrm{X}$} & & \\
\hline & $12-117$ & $X$ & $\mathrm{X}$ & $\mathrm{X}$ & & & & & \\
\hline & $12-118$ & $\mathrm{X}$ & $\mathrm{X}$ & $\mathrm{X}$ & $\mathrm{X}$ & & & & \\
\hline & $12-119$ & $\mathrm{X}$ & $\mathrm{X}$ & & $X$ & & & & \\
\hline & $12-120$ & $\mathrm{X}$ & $\mathrm{X}$ & & & & $\mathrm{X}$ & & \\
\hline & $12-121$ & $\mathrm{X}$ & $\mathrm{X}$ & & $X$ & $\mathrm{X}$ & $\mathrm{X}$ & & \\
\hline & $12-122$ & $X$ & $\mathrm{X}$ & $X$ & $X$ & $\mathrm{X}$ & & & \\
\hline & $12-123$ & $\mathrm{X}$ & $\mathrm{X}$ & $X$ & $X$ & & $X$ & & \\
\hline & $12-124$ & $\mathrm{X}$ & $\mathrm{X}$ & & $\mathrm{X}$ & & $\mathrm{X}$ & & \\
\hline & $12-125$ & $\mathrm{X}$ & $\mathrm{X}$ & & $X$ & $\mathrm{X}$ & $\mathrm{X}$ & & \\
\hline & $12-126$ & $X$ & $\mathrm{X}$ & & & $\mathrm{X}$ & $\mathrm{X}$ & & $X$ \\
\hline
\end{tabular}


Tabela 6. Resultados de análises petrográficas e químicas realizadas no poço de exploração CBM 001-MO-RS. Rr: Refletância Rrandom (\%); cinza, M.V.: matéria volátil; C.F.: Carbono Fixo; PCS: poder calorífico superior.

Table 6. Results from petrographic and chemical analysis performed on coal samples of exploration borehole CBM 001-MO-RS. Rr: Rrandom Reflectance (\%); ash, M.V.: volatile matter; C.F.: fixed carbon; PCS: upper calorific value.

\begin{tabular}{|c|c|c|c|c|c|c|c|}
\hline \multicolumn{4}{|c|}{ Petrografia } & \multicolumn{4}{|c|}{ Análises Químicas } \\
\hline \multirow{2}{*}{ Camada } & \multirow{2}{*}{ Amostra } & \multirow{2}{*}{$\operatorname{Rr}(\%)$} & \multirow{2}{*}{ rank $^{1}$} & Cinzas & M.V. & C.F. & PCS \\
\hline & & & & $\%$ m.(bs.) $)^{2}$ & \multicolumn{2}{|c|}{$\%$ m. (bs.sc.) ${ }^{3}$} & (KCal/Kg) \\
\hline B & $12-086$ & 4,75 & Meta Antracito & 60,2 & 15,8 & 23,9 & 1227 \\
\hline $\mathrm{C}$ & $12-087$ & 3,18 & Antracito & 65,7 & 10,3 & 24,1 & 2207 \\
\hline $\mathrm{D}$ & $12-088$ & 2,45 & Semi Antracito & 67,9 & 11,8 & 20,3 & 1855 \\
\hline $\mathrm{E}$ & $12-089$ & 2,00 & Semi Antracito & 70,1 & 10,4 & 19,5 & 1869 \\
\hline F superior & $12-090$ & 0,91 & Betuminoso Alto Volátil A & 61,0 & 15,2 & 23,8 & 2611 \\
\hline F inferior & $12-091$ & 0,71 & Betuminoso Alto Volátil B & 58,4 & 18,6 & 23,0 & 2667 \\
\hline
\end{tabular}
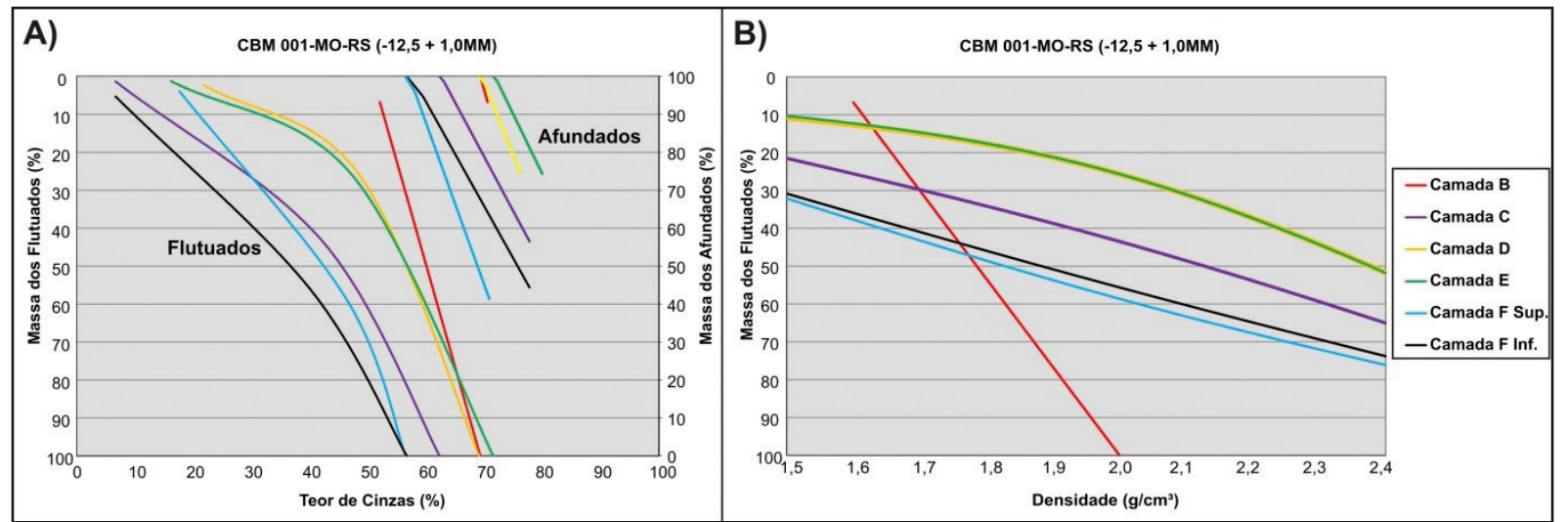

Figura 12. Curvas de lavabilidade dos testes de afunda-flutua, realizados nas amostras de camada do poço de exploração CBM 001-MO-RS. A) Curvas de flutuados e afundados; B) Curvas densimétrica modificado de Sampaio \& Tavares (2005).

Figure 12. Washability curves of the sink float testing performed on coal samples from exploratory borehole CBM-001-MO-RS.: A) Sink float curves; B) Gravity curves modified from Sampaio \& Tavares (2005).

Tabela 7. Resultados dos testes de afunda flutua realizados nas amostras de carvão do poço CBM 001-MO-RS. Table 7. Sink and float tests results performed on coal samples from the borehole CBM 001-MO-RS.

\begin{tabular}{ccccc}
\hline Camadas & Densidade & $\begin{array}{c}\text { Rendimento } \\
\text { (\%massa) }\end{array}$ & $\begin{array}{c}\text { Cinza } \\
\text { (\% em massa, bs.) }\end{array}$ & $\begin{array}{c}\text { PCS } \\
\text { (Kcal/Kg) }\end{array}$ \\
\hline \multirow{2}{*}{ B } & Bruta & & 60,2 & 1.227 \\
& $1,6-2,0$ & 6,7 & 52,1 & 2.341 \\
& $>2,0$ & 93,3 & 70,6 & 1.269 \\
C & Bruta & & 64,7 & 2.207 \\
& $<1,5$ & 1,3 & 6,7 & 7.659 \\
& $1,5-2,0$ & 42,1 & 43,4 & 2.728 \\
D & $>2,0$ & 56,5 & 77,8 & 1.019 \\
& Bruta & & 67,6 & 1.855 \\
& $<1,6$ & 2,2 & 21,8 & 6.134 \\
& $1,6-2,0$ & 23,4 & 51 & 3.619 \\
E & $>2,0$ & 74,3 & 76,3 & 920 \\
& Bruta & & 69,4 & 1.869 \\
& $<1,6$ & 1,2 & 16,2 & 6.805 \\
& $1,6-2,0$ & 24,4 & 48,7 & 3.106 \\
F superior & $>2,0$ & 74,3 & 80 & 843 \\
& Bruta & & 59,8 & 2.611 \\
& $<1,5$ & 3,9 & 17,7 & 6.659 \\
& $1,5-2,0$ & 54,7 & 48,4 & 3.413 \\
& $>2,0$ & 41,4 & 70,9 & 1.480 \\
\hline
\end{tabular}




\section{Conclusões}

A perfuração do poço de exploração CBM 001-MO-RS atingiu uma profundidade máxima de $387,30 \mathrm{~m}$, interceptando sedimentos inconsolidados recentes e o substrato rochoso composto pelas rochas sedimentares das formações Botucatu, Rio do Rasto, Estrada Nova, Irati, Palermo e Rio Bonito até as rochas graníticas do embasamento. A Formação Rio Bonito, portadora dos estratos alvo do estudo, foi encontrada entre as profundidades de 300,00 a $385,76 \mathrm{~m}$.

Foram identificadas cinco camadas de carvão e um leito carbonoso na Formação Rio Bonito, totalizando 9,77 m de carvão, no qual predominam litotipos do tipo carvão fosco e carvão fosco bandado. Sotoposto ao intervalo carbonoso, foi identificada uma intrusão ígnea de aproximadamente 18 $\mathrm{m}$ de espessura. Esta alterou termicamente todas as camadas de carvão do perfil. A influência térmica, como ficou evidente nos resultados de refletância da vitrinita, apontou uma tendência de correlação exponencial entre proximidade da intrusão e o aumento dos valores de refletância da vitrinita variando de 0,61 a 4,52 $\mathrm{Rr}(\%)$.

Além disto, pode-se, possivelmente, creditar a inexistência da camada A no perfil à influência causada pela intrusão ígnea, que ao intrudir o perfil carbonoso, consumiu por completo a mesma, tendo em vista que o local perfurado apresentava potencial para existência da camada A.

$\mathrm{Na}$ porção inferior do intervalo carbonoso composta pela camada F, ocorre predomínio do grupo maceral vitrinita; já na porção superior, há uma preponderância do grupo maceral inertinita.

Vitrinita exibiu para a camada F um trend de diminuição dos seus volumes no sentido base para topo da camada. A inertinita exibe um comportamento inversamente proporcional. 0 grupo maceral Liptinita ocorre de forma significativa somente na camada F; sua ausência na porção superior do intervalo tem relação com as altas temperaturas da intrusiva. Dentro dos constituintes da matéria mineral, a argila é o mais abundante; secundariamente ocorrem, quartzo, pirita e carbonato. Importante destacar a presença de coque natural nas amostras próximas à intrusão.

Faz-se interessante notar o comportamento do conteúdo de matéria mineral na camada $F$, que apresenta uma correlação positiva com os teores de pirita e de liptinita, relacionada a pulsos transgressivos, responsáveis por causar a entrada de água salina e sedimento siliciclástico no ambiente de turfeira. Tais tentativas de interpretação não são passíveis de serem realizadas na porção supe- rior do perfil, pois esta zona foi submetida à alteração térmica intensa da intrusão, como evidenciado nas medidas de refletância da vitrinita.

A pirita é identificada até a camada D, não sendo observável na parte superior do intervalo carbonoso, possivelmente relacionada com a influência térmica causada pela intrusão, dada a baixa temperatura de volatilização de tal mineral.

Observaram-se altos teores de cinzas na maioria das amostras, conduzindo a se classificar $67 \%$ das amostras como rocha carbonosa, enquanto 33 $\%$ podem ser classificadas como carvão de categoria muito inferior. Tendo-se em consideração valores médios para as camadas, observou-se que a camada F é classificada como carvão de qualidade muito inferior. As outras quatro camadas e o leito carbonoso são classificados como rocha carbonosa.

O conteúdo de matéria volátil apresentou valores com uma variação de 5,76 a 30,69 \% em peso, tendo uma correlação inversamente proporcional com os valores de refletância da vitrinita. Os valores de poder calorífico superior obtidos mostraram uma elevada variação desde o menor valor de $777 \mathrm{Kcal} / \mathrm{Kg}$ até o valor máximo de $4.732 \mathrm{Kcal} /$ $\mathrm{Kg}$, com relação inversa de proporcionalidade com o teor de cinzas. Na caracterização da mineralogia, foram encontrados sistematicamente quartzo, caulinita, ilita e plagioclásio e de forma esporádica, ankerita, calcita, dolomita e pirita.

Nos ensaios de afunda-flutua, as amostras ensaiadas não demonstram uma boa separação entre componentes orgânicos e inorgânicos no beneficiamento gravimétrico. É observado um baixíssimo rendimento na obtenção de produtos com baixo teor cinza. Para produtos menos nobres, com teor de cinza na faixa dos $45 \%$, é passível de se obter um rendimento de até $50 \%$ de volume nas camadas $\mathrm{F}$ superior e inferior e na camada $\mathrm{C}$, camadas que melhor se portaram nos testes de beneficiamento e apresentam viabilidade comercial.

Agradecimentos - Aos autores agradecem ao CNPq pelo suporte financeiro através do Projeto 551239/2010-7, pela bolsa de mestrado (130006/2013-0) e pela bolsa de produtividade em pesquisa (302238/2014-0) e à FAPERGS através do projeto de pesquisa PRONEX 10/0025-9; à Carbonífera Metropolitana S.A. por ter disponibilizado auxílio financeiro, logístico e apoio técnico na execução do poço exploratório para obtenção das amostras de carvão, assim como ter realizado parte das análises do presente trabalho, como parte principal da Dissertação de Mestrado do primeiro autor Junto ao Programa de Pós-graduação em Geociências da Universidade Federald o Rio Grande do Sul. 


\section{Referências}

Aboarrage, A.M. \& Lopes, R. da C. 1986. Projeto a borda leste da bacia do Paraná: integração geológica e avaliação econômica. Porto Alegre, DNPM/CPRM, $18 \mathrm{v}$.

ABNT. Associação Brasileira de Normas Técnicas. 1983 1983a, 1983b, 1983c e 1983c. Carvão mineral: determinação de umidade. Rio de Janeiro, ABNT, 6p. (NBR 8293).

ABNT. Associação Brasileira de Normas Técnicas. 1983. Carvão mineral: determinação do teor de cinzas. Rio de Janeiro, ABNT, 7p. (NBR 8289).

ABNT. Associação Brasileira de Normas Técnicas. 1983. Carvão mineral: determinação do teor de matéria volátil. Rio de Janeiro, ABNT, 6p. (NBR 8290).

ABNT. Associação Brasileira de Normas Técnicas. 1983. Carvão mineral: determinação do enxofre total pelo processo de combustão. Rio de Janeiro, ABNT, 7p. (NBR 8295).

ABNT. Associação Brasileira de Normas Técnicas. 1984. Carvão mineral: determinação do poder calorífico superior e do poder calorífico inferior - método de ensaio. Rio de Janeiro, ABNT, 9p. (NBR 8628).

ABNT. Associação Brasileira de Normas Técnicas. 1985. Ensaios densimétricos. Rio de Janeiro, ABNT, 9p. (NBR 8738).

ANEEL. Agência Nacional de Energia Elétrica. 2008. Atlas de Energia Elétrica do Brasil. Brasília, ANEEL, 236p.

ASTM. American Society for Testing and Materials. 2007. Standard practice for preparing coal samples for analysis. Philadelphia, PA. Annual Book of ASTM Standards. Section 5, Petroleum Products, Lubricants, and Fossil Fuels, V. 05.06: Gaseous Fuels; Coal and Coke, 11p. (D 2013).

Bortoluzzi, C.A., Piccoli, A.E.M., Corrêa da Silva, Z.C., Cazzulo-Klepzig, M., Dias-Fabrício, M.E., Silva Filho, B.C. da, Guerra-Sommer, M., Marques-Toigo, M., Bossi, G.E. \& Andreis, R.S. 1980. Estudo geológico da bacia carbonífera de Gravataí-Morungava, RS. In: CONGRESSO BRASILEIRO DE GEOLOGIA, 31., 1980, Camboriú. Anais... Camboriú, SBG, v. 1, p. 266-282.

Bossi, G.E \& Piccoli, A.E.M. 1980. Estudo de sequências sedimentares, formação Rio Bonito, área de Gravataí-Morungava, RS. Pesquisas em Geociências, 13: 6389.

Bossi, G.E. \& Piccoli, A.E.M. 1979. Interpretações paleogeográficas na Bacia do Paraná, nordeste do Rio Grande do Sul. Grupo Itararé. In: II SIMPÓSIO REGIONAL DE GEOLOGIA, 1979, Rio Claro, SP. Anais..., Rio Claro, p. 26-27.

Bustin, R.M., Cameron, A., Grieve, D. \& Kalkreuth, W. 1983. Coal petrology - its principles, methods and applications. 3nd ed. Victoria, British Columbia, Geological Association of Canada, Short Course Notes, 230 .

Corrêa da Silva, Z.C. 2004. Coal facies studies in Brazil: a short review. International Journal of Coal Geology, 58(4):119-124.

Diessel, C. F. K. 1965. Correlation of macro-and micro- petrography of some New South Wales coals. Proceedings. In: COMMENWEALTH MINING AND METALLURGICAL CONGRESS, 8. 1965, Australia and New Zealand. Reports.... v.6, p. 669-677.

EPE. Empresa de Pesquisa Energética (Brasil). 2015. Balanço energético nacional. Rio de Janeiro, EPE, $155 p$.

Ferreira, J.A.F., Santos, A.P.E. \& Süffert, T. 1978. Projeto Carvão no Rio Grande do Sul, Relatório final. Porto Alegre, Convênio DNPM/CPRM, vol. I a IX.

Gomes, A.P., Ferreira, A.A.F., Albuquerque, L.F. de. \& Suffert, T. 1998. Carvão Fóssil. Estudos Avançados, 12(33): 89-106.

ICCP. International Committee for Coal and Organic Petrology. 1971. International handbook of coal petrography, 2a ed. Paris, ICCP, Centre National de La Recherche Scientifique. Supplement, 494p.

ICCP. International Committee for Coal and Organic and Petrology. 1998. The new vitrinita classification, ICCP System. Fuel. 77: 349-358.

ICCP. International Committee for Organic and Coal Petrology. 2001. The new inertinita classification, ICCP System. Fuel. 80: 459-471.

IEA. International Energy Agency. 2010. World energy outlook. Paris, IEA PUBLICATIONS, 738p. Disponível em: <http://www.worldenergyoutlook.org/media/ weo2010.pdf>. Acesso em: 07 dez. 2016.

ISO. International Organization for Standardization. 2009a. Methods for the Petrographic Analysis of coals. Part 5: Method of determining Microscopically the Reflectance of Vitrinite. International Organization for Standardization. 14p. (7404/5).

ISO. International Organization for Standardization. 2009b. Methods for the Petrographic Analysis of coals. Part 3. Methods of determining maceral group composition. International Organization for Standardization. 8p. (7404/3).

Kalkreuth, W., Holz, M.L. Kern, M.L., Machado, G., Mexias, A., Silva, M.B., Willet, J., Finkelman, R. \& Burger, H. 2006. Petrology and chemistry of Permian coals from the Paraná Basin: 1. Santa Terezinha, Leão Butiá and Candiota Coalfields, Rio Grande do Sul, Brasil. International Journal of Coal Geology, 68(12): 79-116.

Kalkreuth, W., Holz, M., Mexias, A., Balbinot, M., Levandowski, J., Willet, J., Finkelman, R. \& Burger, H. 2010. Deposicional setting, petrology and chemistry of Permian coals from the Paraná Basin: 2. South Santa Catarina Coalfield, Brazil. International Journal of Coal Geology, 84: 213-236.

Levandowski, J.H. 2013. Características petrográficas e geoquímicas das camadas de carvão do poço CBM 001-CL-RS, jazida Chico Lomã, e sua relação com Coalbed Methane associado. Porto Alegre, 167p. Tese de doutorado, Programa de Pós-Graduação em Geociências, Instituto de Geociências, Universidade Federal do Rio Grande do Sul.

Marchioni, D. \& Kalkreuth, W. 1991. Coal facies interpretations based on lithotype and maceral variations in Lower Cretaceous (Gates Formation) coals of Western Canada. International Journal of Coal Geology, 
18(1-2): 125-162.

Mastalerz, M., Drobniak, A. \& Schimmelmann, A. 2009. Changes in optical properties chemistry and micropore and mesopore characteristics of bituminous coal at the contact with dikes in the Illinois Basin. International Journal of Coal Geology, 77(3-4): 310319.

Milani, E.J. 2000. Geodinâmica fanerozóica do Gondwana sul-ocidental e a evolução geológica da Bacia do Paraná. In: Holz, M., De Ros, L.F. (Eds.). Geologia do Rio Grande do Sul. Porto Alegre, CIGO/UFRGS, p. 275-302.

Milani, E.J., Melo, J.H.G., Souza, P.A., Fernandes, L.A. \& França, A.B. 2007. Bacia do Paraná. Boletim de Geociências da Petrobras, 15: 265-287.

Sampaio, C.H. \& Tavares, L.M.M. 2005. Beneficiamento gravimétrico: uma introdução aos processos de concentração mineral e reciclagem de materiais por densidade. Porto Alegre, Editora UFRGS, 603p.

Schneider, R.L., Mühlmann, H., Tommasi, E., Medeiros, R.A., Daemon, R.F. \& Nogueira, A.A. 1974. Revisão Estratigráfica da Bacia do Paraná. In: CONGRESSO BRASILEIRO DE GEOLOGIA, 28., 1974, Porto Alegre. Anais... Porto Alegre, SBG, v.1, p. 41-66.

Simão, G. 2012. O carvão da camada Bonito, Jazida Sul Catarinense: uma contribuição para a caracterização petrográfica, química e tecnológica. Porto Alegre, 92p. Monografia de Conclusão de Curso, Curso de Geologia, Instituto de Geociências, Universidade Federal do Rio Grande do Sul.

Simão, G. \& Kalkreuth, W. 2015. Petrographic and chemical characterization of the Bonito Seam and its be-

Manuscrito 596

Editores: Ana Maria P. Mizusaki \& Paulo A. Souza neficiation products, South Santa Catarina Coalfield - Brazil. Energy Exploration \& Exploitation, 33(1): 75-90.

Silva, M.B. 2012. Classificação internacional do carvão (CEE-NU) da Camada Inferior, Mina do Leão, RS, Brasil. Revista Escola de Minas, 65(1): 29-33.

Stopes, M.C. 1919. On the four visible ingredients in banded bituminous coals. Proceedings of the Royal Society, 90: 470-487.

Süffert, T., 1997. Carvão nos Estados do Rio Grande do Sul e Santa Catarina. Porto Alegre CPRM, 40p. (Relatório interno).

Taylor, G.H., Teichmüller, D.A., Diessel, C.F.K., Littke, R. \& Robert, P. 1998. Organic Petrology. Berlin, Springer-Verlag, 704p.

Thomaz-Filho, A.T., Mizusaki, A.M.P. \& Antoniolli, L. 2008. Magmatismo nas bacias sedimentares brasileiras e sua influência na geologia do petróleo. Revista Brasileira de Geociências, 38(2): 128-137.

UN. United Nations. 1998. International Classification of in-seam coals. Geneva, Economic Commission for Europe, Committee on Sustainable Energy, United Nations, 41p.

Zalán, P.V., Wolff, S., Conceição, J.C.J., Marques, A., Astolfi, M.A., Vieira, I.S., Appi, C.J. \& Zanoto, O.A. 1990. Bacia do Paraná. In: Cabaglia, G.P.R. \& Milani, E.J. (Ed.). Origem e evolução das bacias sedimentares. Rio de Janeiro, Petrobrás, p. 135-168.

Zanini, L.F.P. \& Pimentel, G.B. 2006. Mapa das Jazidas de Carvão Mineral. Porto Alegre, CPRM - Serviço Geológico do Brasil, 1v., escala 1:250.000. 
